\title{
Progress in Additive Manufacturing and Rapid Prototyping
}

\author{
J.-P. Kruth (1), Katholieke Universiteit Leuven, Division PMA, Belgium \\ M.C. Leu* (2), New Jersey Institute of Technolgy, Mech. Eng. Dept., USA \\ T. Nakagawa (1), University of Tokyo, Inst. of Industrial Science, Japan \\ * On leave as Program Director for Manufacturing Machines and Equipment at NSF, USA
}

\begin{abstract}
Rapid prototyping generally refers to techniques that produce shaped parts by gradual creation or addition of solid material, therein differing fundamentally from forming and material removal manufacturing techniques. This paper tries to summarise one decade of research and developments in rapid prototyping. The first part surveys some general economical and technological trends. The second part of the paper goes into some more details on a process-by-process basis.
\end{abstract}

Kerwords: rapid prototyping and manufacturing, additive manufacturing processes.

\section{Introduction: one decade of rapid prototyping}

Industrial application of Rapid Prototyping as material additive manufacturing process started a decade ago (Fig. 1). During that first decade of RP industrialisation, additive manufacturing processes have been a major concern of CIRP's Scientific Technical Committee on Electro-Physical and Chemical Processes (STC-E). This is due to the fact that additive processes apply similar physical and chemical phenomena to progressively add material as the ones used for selective material removal in the so-called non-traditional manufacturing processes dealt with originally by STC-E: see table 1 [52].

in 1991, CIRP's STC-E devoted a first keynote paper to a survey of rapid prototyping [51]. The present STC-E paper reiterates such stateof-the-art and surveys one decade of innovation in additive manufacturing.

Table 1: Examples of physical and chemical phenomena in material removal and material addition manufacturing (Exhaustive list and references in [52])

\begin{tabular}{|l|l|l|}
\hline $\begin{array}{l}\text { Phenomena } \\
\text { processes }\end{array}$ & $\begin{array}{l}\text { Materlal removal processes } \\
\text { Electro-chemical machining }\end{array}$ & $\begin{array}{l}\text { Material addition processes } \\
\text { (photo-polymensation) } \\
\text { Laser-induced CVD }\end{array}$ \\
\hline $\begin{array}{l}\text { Thermo- } \\
\text { physical } \\
\text { processes }\end{array}$ & $\begin{array}{l}\text { Laser beam machining } \\
\text { Plasma beam machining } \\
\text { Electron beam machining } \\
\text { Electro discharge machining }\end{array}$ & $\begin{array}{l}\text { Selective laser sintering } \\
\text { Plasma spraying* } \\
\text { Electron beam sintering* } \\
\text { Electro-discharge deposition* }\end{array}$ \\
\hline $\begin{array}{l}\text { Liquid jet } \\
\text { processes }\end{array}$ & Water jet machining & 3D ink jet prinling \\
\hline $\begin{array}{l}\text { Solid jet } \\
\text { processes }\end{array}$ & Abrasive jet machining & Powder jet laser cladding \\
\hline $\begin{array}{l}\text { Utrasonic } \\
\text { processes }\end{array}$ & Ulirasonic machining & N/A \\
\hline
\end{tabular}

: not applied commercially

Although most rapid prototyping processes in use today were already known in 1991 [51], most of them were still in a pre-commercial development stage. A few systems didn't reach the commercialisation stage yet, but most of them did, although sometimes painfully [101]. In fact, we were to wait until about 1993 to see 3D Systems' stereolithography process as first one, followed by other companies, to become really successful on the market: Fig. 1 [101]. In 1997, 1057
RP machines were sold, which brought the total of installed RP machines to some 3289 units. The most popular RP systems today are Stereo-Lithography (SL), Fused Deposition Modelling (FDM), Ink Jet Printing (IJP), Laminated Object Manufacturing (LOM) and Selective Laser Sintering (SLS): Table 2.

Table 2: Most successful industrial RP systems

\begin{tabular}{|c|c|}
\hline Process & Vendor sales in 1997 \\
\hline Stereo-Lithography (SL) & 30 Systems: 165 units (16\%) \\
\hline \multirow[t]{2}{*}{281 units $\quad(26 \%)$} & Japanese vendors: 97 units (9\%) \\
\hline & EOS-Stereos: 22 unils $(2 \%)$ \\
\hline Fused Dep. Mod. (FOM) & Stratasys: 260 units $(25 \%)$ \\
\hline Ink Jet Printing (IJP) & Sanders: 152 units (14\%) \\
\hline 265 units $(26 \%)$ & 3D Systems: 113 units (11\%) \\
\hline Laminated Object Mfg. (LOM) & Helysis: 76 units $(7 \%)$ \\
\hline \multirow{3}{*}{$\begin{array}{r}98 \text { units } \\
\text { [162 units }\end{array}$} & Kira: 20 units $(2 \%)$ \\
\hline & Kinergy: $>2$ units \\
\hline & [Schrott: 64 units (4\%)] \\
\hline \multirow{2}{*}{$\begin{array}{l}\text { Selective Laser Sintering (SLS) } \\
\qquad 75 \text { units } \quad(7 \%)\end{array}$} & DTM: 42 units ( $4 \%$ ) \\
\hline & EOSint: 33 units (3\%) \\
\hline
\end{tabular}

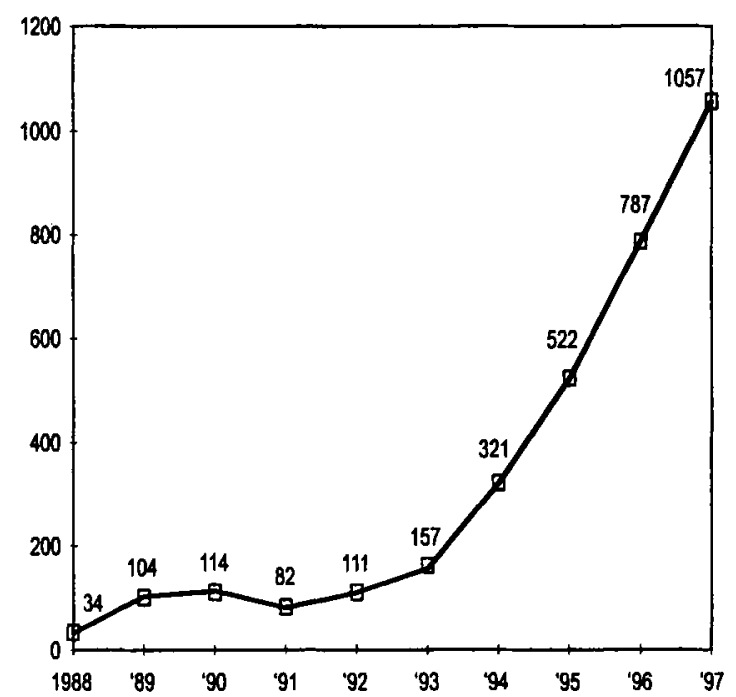

Fig. 1: World-wide Rapid Prototyping unit sales [101] 


\section{Processes}

A technical overview of the RP systems in industrial use today is given in Table $3[61,72]$. The processes are classified according to the type of bulk material used: liquid, powder, solid layers or gas $[51,61]$. Gasbased systems are not yet commercially available, but are mentioned for completeness, logether with few academic processes.

Description of those systems can be found in $[51,52,61]$ and will be briefly recalled in further sections when appropriate.

\section{General Trends and Novelties}

This section summarises the major trends in rapid prototyping across various processes. Further sections deal with novelties on a processby-process basis.

\subsection{Speed increase}

Although the actual production speed of rapid prototyping processes remain slow as compared to conventional manufacturing processes like forming or cutting, the first decade of RP development already allowed to cut down machining times by some factor of ten (10). Fig. 2 shows data related to Fused Deposition Modeling. The example of Fig. 3 relates to the production of a human skull by stereo-lithography. Production time could be reduced from 30 to 3 hours. This

Table 3: List of industrial additive manufacturing processes

\begin{tabular}{|c|c|c|c|c|c|c|c|}
\hline $\begin{array}{l}\text { Sup- } \\
\text { ply }\end{array}$ & Process & Lay-out & $\begin{array}{l}\text { Layer creation } \\
\text { technique }\end{array}$ & $\begin{array}{l}\text { Phase Change during } \\
\text { layer solidification }\end{array}$ & Materials & $\begin{array}{l}\text { Variants } \\
\text { Laser based }\end{array}$ & Systems \\
\hline \multirow{8}{*}{$\begin{array}{l}\mathrm{L} \\
1 \\
0 \\
U \\
1 \\
0\end{array}$} & \multirow[t]{2}{*}{$\begin{array}{l}\text { Stereo- } \\
\text { Lithography } \\
\text { (SL) }\end{array}$} & \multirow[t]{2}{*}{$\begin{array}{l}\text { Liquid } \\
\text { resin } \\
\text { in a vat }\end{array}$} & \multirow[t]{2}{*}{$\begin{array}{l}\text { Liquid layer } \\
\text { deposition }\end{array}$} & \multirow[t]{2}{*}{ Photo-polymerization } & \multirow[t]{2}{*}{$\begin{array}{l}\text { Photo-polymers: } \\
\text { - acrylates } \\
\text { - epoxies } \\
\text { - filled resins } \\
\text { (glass, ceramic, metal,...) } \\
\text { - colorable resins }\end{array}$} & $\begin{array}{l}\text { Laser } \\
\text { illumination }\end{array}$ & $\begin{array}{l}\text { 3D System - SLA (US) } \\
\text { NTT Data CMET-SOUP (J) } \\
\text { D-MEC/Sony - SCS (J) } \\
\text { [EOS - Stereos (D)]2 } \\
\text { MEIKO-Colamm (J) } \\
\text { Teijin Seiki (Dupont)-Solitom (J) } \\
\text { Aaroflex (Dupont) - Solid Imager } \\
\text { Denken - SLP (J) (US) } \\
\text { Fockele \& Schware (D) } \\
\text { Ushio - Unirapid (J) }\end{array}$ \\
\hline & & & & & & $\begin{array}{l}\text { Flash lamp + } \\
\text { milling layers }\end{array}$ & Cubital - SCG (Isr) \\
\hline & \multirow[t]{3}{*}{$\begin{array}{l}\text { Fused } \\
\text { Deposition } \\
\text { Modeling } \\
\text { (FDM) }\end{array}$} & \multirow[t]{3}{*}{$\begin{array}{l}\text { Material } \\
\text { melted } \\
\text { in nozzle }\end{array}$} & \multirow[t]{3}{*}{$\begin{array}{l}\text { Continuous } \\
\text { extrusion and } \\
\text { deposition }\end{array}$} & \multirow[t]{3}{*}{ Solidification by cooling } & $\begin{array}{l}\text { Polymers: (ABS, PA, ...) } \\
\text { Wax } \\
\text { Filled polymers (glass,...) }\end{array}$ & FDM & $\begin{array}{l}\text { Stratasys - FDM (US) } \\
\text { Stratasys - Genisys (US) }\end{array}$ \\
\hline & & & & & Metals with binder & MJS & Development [IFAM (D)] \\
\hline & & & & & Ceramics with binder & FDC & Development [Austin, Rutgers] \\
\hline & \multirow{3}{*}{$\begin{array}{l}\text { Ink } \\
\text { Jet } \\
\text { Printing } \\
\text { (IJP) }\end{array}$} & \multirow{3}{*}{$\begin{array}{l}\text { Droplets } \\
\text { of molten } \\
\text { material }\end{array}$} & \multirow{3}{*}{$\begin{array}{l}\text { Drop-on- } \\
\text { demand } \\
\text { deposition }\end{array}$} & \multirow[t]{3}{*}{ Solidification by cooling } & \multirow{3}{*}{$\begin{array}{l}\text { Polymers } \\
\text { Wax }\end{array}$} & & 3D System-Actua (US) \\
\hline & & & & & & milling layers & Sanders - ModelMaker (US) \\
\hline & & & & & & $\begin{array}{l}\text { 5-axis milling } \\
\text { layer + contour }\end{array}$ & Development [Staniord] \\
\hline \multirow{6}{*}{$\begin{array}{l}P \\
0 \\
W \\
D \\
E \\
R\end{array}$} & \multirow{3}{*}{$\begin{array}{l}\text { Three } \\
\text { Dimensional } \\
\text { Printing } \\
\text { (3D-P) }\end{array}$} & \multirow{3}{*}{$\begin{array}{c}\text { Binder } \square \rightarrow \\
y\end{array}$} & \multirow{3}{*}{$\begin{array}{l}\text { Layer of } \\
\text { powder }+ \\
\text { Drop-on- } \\
\text { demand binder } \\
\text { printing }\end{array}$} & \multirow[t]{3}{*}{ No phase change } & Ceramics with binder & & Soligen-DSPC (US) \\
\hline & & & & & Metals with binder & & Extruhone-3DP (US) \\
\hline & & & & & Polymer with binder & & Z-corp.-3DP (US) \\
\hline & $\begin{array}{l}\text { Selective } \\
\text { Laser } \\
\text { Sintering } \\
\text { (SLS) }\end{array}$ & & $\begin{array}{l}\text { Layer of } \\
\text { powder }\end{array}$ & $\begin{array}{l}\text { Laser sintering/ } \\
\text { Laser melting \& } \\
\text { resodification by } \\
\text { cooling }\end{array}$ & $\begin{array}{l}\text { Polymers (PC, } \mathrm{PA}, \ldots \text { ) } \\
\text { Filled polymers (glass,...) } \\
\text { Metals with binder } \\
\text { Metals (pure) } \\
\text { Sand, ceramics }\end{array}$ & Laser-based & $\begin{array}{l}\text { DTM - Sinterstation (US) } \\
\text { EOS - EOSint (D) }\end{array}$ \\
\hline & \multirow[t]{2}{*}{$\begin{array}{l}\text { Laser } \\
\text { Cladding }\end{array}$} & \multirow{2}{*}{ Laser } & \multirow[t]{2}{*}{$\begin{array}{l}\text { Continuous } \\
\text { injection of } \\
\text { powder }\end{array}$} & \multirow[t]{2}{*}{$\begin{array}{l}\text { Laser melling \& } \\
\text { solidfication by cooling }\end{array}$} & \multirow[t]{2}{*}{ Metais } & $\begin{array}{l}\text { Laser } \\
+ \text { milling layer } \\
\text { and contour }\end{array}$ & Röders - CMB (D) \\
\hline & & & & & & Laser-based & $\begin{array}{l}\text { Development: } \\
\text { - LENS [Sandia] } \\
\text { - LAPS-J [IPK (D)] } \\
\end{array}$ \\
\hline \multirow{7}{*}{$\begin{array}{l}S \\
0 \\
L \\
1 \\
D\end{array}$} & \multirow{7}{*}{$\begin{array}{l}\text { Laminated } \\
\text { Object } \\
\text { Manufactur. } \\
\text { (LOM) }\end{array}$} & \multirow{7}{*}{$\begin{array}{l}\text { Feeding. } \\
\text { cutting and } \\
\text { binding } \\
\text { of sheets }\end{array}$} & \multirow[t]{7}{*}{$\begin{array}{l}\text { Deposition of } \\
\text { sheel material }\end{array}$} & \multirow[t]{7}{*}{ No phase change } & \multirow[t]{2}{*}{ Paper } & Laser cutting & $\begin{array}{l}\text { Helisys-LOM (US) } \\
\text { Kinergy-ZIPPY (Sing.) }\end{array}$ \\
\hline & & & & & & Knife cutting & Kira - SAHP (J) \\
\hline & & & & & Polymer & Knife culting & [SPARX-(Sweden)] \\
\hline & & & & & Polymer foam & $\begin{array}{l}\text { Heated wire } \\
\text { culting }\end{array}$ & Development [Utah] \\
\hline & & & & & Composites & Laser cutting & Helisys-LOM (US) \\
\hline & & & & & Ceramics & Laser cutting & Development [Dayton] \\
\hline & & & & & Metals & Laser cutting & $\begin{array}{l}\text { Semi-industrial [U. Tokyo, } \\
\text { U. Erlangen (D), CRIF(B)] }\end{array}$ \\
\hline $\begin{array}{l}\text { G } \\
\text { A } \\
\text { S }\end{array}$ & $\begin{array}{l}\text { Selective } \\
\text { Laser Chem. } \\
\text { Vapour } \\
\text { Deposition }\end{array}$ & $\begin{array}{l}\text { Laser }= \\
\text { Gas } \\
\text { out } \\
\text { out }\end{array}$ & $\begin{array}{l}\text { Condensation } \\
\text { of gas }\end{array}$ & $\begin{array}{l}\text { Forming solid from gas } \\
\text { by chemical reaction }\end{array}$ & $\begin{array}{l}\text { Metals (Al, FeNi,...) } \\
\text { Ceramics (SiC,...) }\end{array}$ & Laser-based & $\begin{array}{l}\text { Development: } \\
\text { - LCVD [M. Planck-(D)] } \\
\text { - SALD [Connect., Texas, } \\
\text { Renssel.] }\end{array}$ \\
\hline
\end{tabular}

${ }^{2}$ Activity ceased recently 


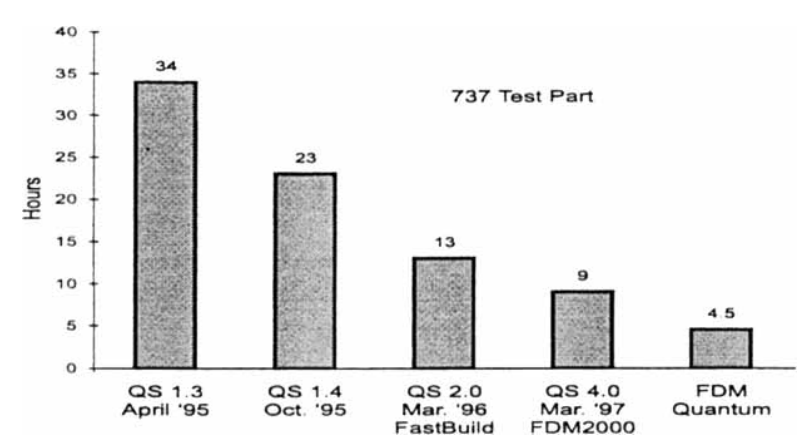

Fig. 2: Time reduction in Fused Deposition Modeling (Stratasys)

acceleration resulted from several improvements that will be discussed below: the use of higher power lasers and better scanning strategies (reduced part curing time), the use of perforated support structures (reduced support curing time) and the development of faster layer deposition or re-coating mechanisms.

This tenfold speed increase may be but a beginning: further developments may reduce production times even further and yield speed increases as those achieved in two decades of development on

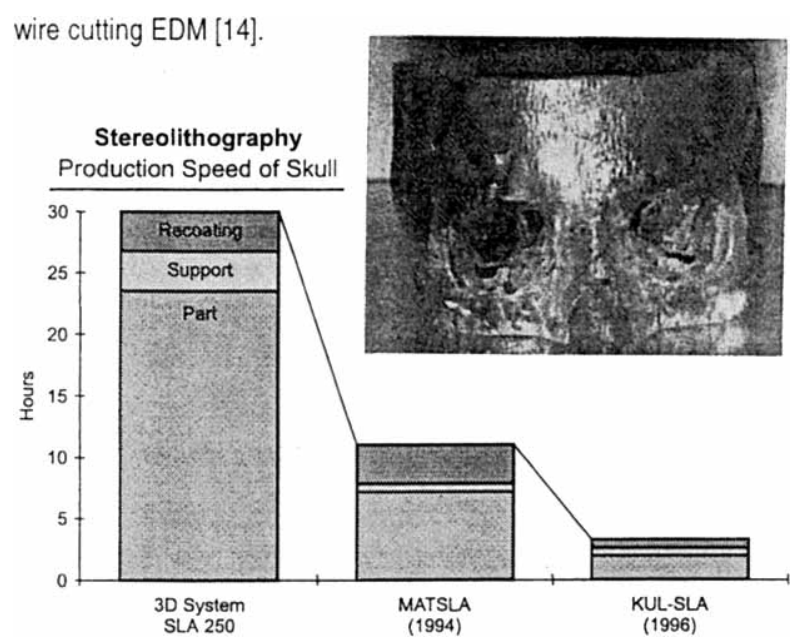

Fig. 3: Time reduction in stereo-lithography (K.U.LeuvenMaterialise)

Examples of such developments are:

- Application of a hexagonal rotating mirror to increase the laser scanning speed (elimination of inertia forces encountered in galvano-scanners) [72]

- Multi (5) optical fibre illumination in stereo-lithography [72]

- Multi piezo printing head for ink jet or 3D printing (up to 1028 on DSPC machines).

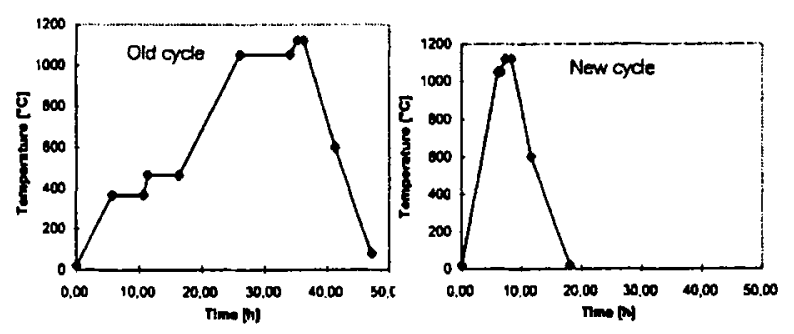

Fig. 4: SLS post-processing cycle for metal (DTM)

Quite some aftention also goes to time reduction or elimination of post-processing activities. Post-curing of stereo-lithography parts in a UV furnace, can today be avoided by using highly reactive photopolymers and very dense, overlapping laser scanning strategies. Fig 4 shows, for instance, how the polymer-binder burn-out and the copper impregnation cycle used for post-processing DTM selective laser sintered steel parts could be reduced drastically by developing improved materials.

\subsection{New manufacturing concept for single day throughput}

The high degree of aulomation makes additive manufacturing processes ideally suited when aiming for short throughput time. Recent developments make it possible today to reduce the total throughput time for one-off parts to one day (24 hours), including quotation, order placement, planning, production and international delivery. Such a one-day production service is offered since the end of 1997 by a Belgian RP service bureau, spin-off of the University of Leuven. The company guarantees that parts ordered before 12.00 CET will be produced in their production plant near Brussels the same day and delivered anywhere in Europe by the next moming. To achieve this aim, several new technologies were combined, some of which were specially developed for this purpose [97]:

- Internet-based communication software

- Automated quotation and production planning

- CAD/CAM/RP software tools

- Fast rapid prototyping processes and machines

- Express carrier

The whole process starts from a CAD/STL part file at the location of the customer and includes the following steps (Fig. 5):

- Log-on: The customer uses a proprietary internet software to log onto the server of the production company.

- Data verification: The STL file of the customer is automatically checked for errors by the client communication software (Errors may be fixed with a STL fixing software).

- Quotation: Significant part data (e.g. height, volume,...) are extracted automatically from this CAD/STL file and transmitted to the server at the production site for automatic price quotation and capacity planning within seconds.

- Ordering: If the customer accept the order (within 30 min. to guarantee capacity reservation for the same day), the STL file is encrypted and compressed (for purpose of confidentiality and data transfer efficiency) and transmitted to the production server. Planning: Production planning (detailed capacity planning, grouping of parts on different RP machines, production and delivery orders) and process planning (part slicing, merging, CAM programming and selection of machining parameters like layer thickness, laser power and scan speed) are performed. Just like quoting, those tasks may be highly automated in case of additive manufacturing, because it consists of single machine, single set-up and toolless operations (no cumbersome selection of tools, set-up, processing sequence, etc.).

- Production: By noon, production is started on specially designed fast stereo-lithography machines. The speed of those machines is guaranteed by some of the developments mentioned in $\$ 3.1$ and described in $\$ 4$. Atter production ( $8 \mathrm{~h}$ max.), parts are cleaned up and packed for delivery.

- Delivery: During production planning, invoices and delivery forms were generaled and forwarded by internet to the express carrier, who prepares all custom and other forms and plans the transportation. Packed parts are delivered by 23.00 p.m. to the carrier for overnight transportation and next morning deliveny. (For reasons of time differences, next morning delivery is presently guaranteed only over the whole of Europe).

Today this one-day manufacturing concept allows production of 'concept models'. Functional prototypes and functional parts cannol yet be produced, because the part's properties (precision, strength,...) are subject to the limitations of the stereo-lithography process used here, and because part finishing is reduced to a minimum (removal of 
excess stereo-lithography resin and support structures, rough polishing if needed, no part painting or coating, etc.). However, this concept could be easily extended in the future to other RP manufacturing processes able to produce high strength polymer, metal or ceramic parts and hence may change fundamentally the way production plants are organised and operated.

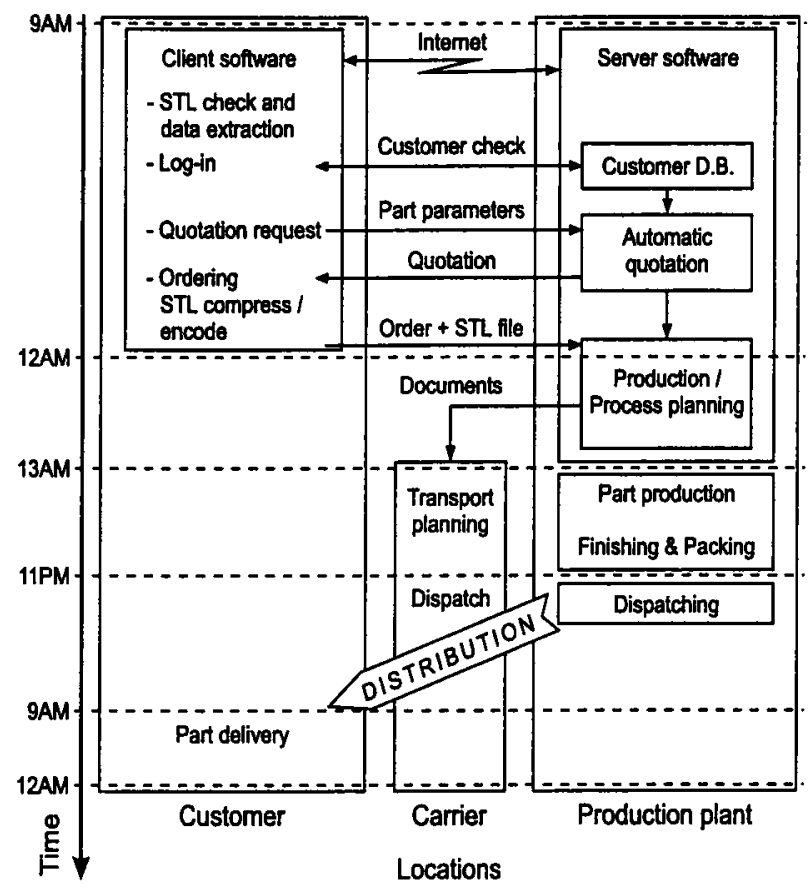

Fig. 5: One-day manufacturing concept (Materialise)

\subsection{Wide range of new materials}

One of the success factors of additive manufacturing in the future could well be its ability to produce complex net or near net shaped parts in materials that are hard to machine conventionally, like hardmetals, ceramics, composites, etc. The early application of additive manufacturing to produce prototypes of plastic parts was already greatly due to this incentive: i.e. the production of net shaped plastic products without need for expensive and time consuming special tools, like injection moulds.

During the past decade, tremendous progress has been achieved in developing new or better materials for additive manufacturing processes. The poor acrylic stereo-lithography materials have been largely replaced by more performant epoxy-based photo-polymers. Fused deposition modelling is now possible with ABS instead of nylon or wax. Selective laser sintering can now be applied directly (i.e. without use of polymer binder) to metals like bronze, steel, hardmetal (WC/Co), or to ceramics $\left(\mathrm{SiC}, \mathrm{Al}_{2} \mathrm{O}_{3}\right)$. Even sand casting moulds are now industrially produced by SLS.

Today, parts in basically any materials can be produced by one or another additive manufacturing process: polymers (thermoplastics, thermosetters, photo-polymers), metals, ceramics, wood-like parts, composites.

Most of all, material additive processes are, by their basic principle of gradually creating or adding material, ideal to produce all kinds of composite parts. A few examples are:

- Laminated object manufacturing is ideally suited to produce laminated fibre composite parts by stacking and binding glass or carbon fibres laminates, fabrics and other sheet like prepregs [46].

- Stereo-Lithography has been used successfully to produce fibre reinforced plastic components filled with long (Fig. 6) or short (Fig. 15) fibres [26,76].
- Metal composites, combining a high strength structural metal having a high melting point with a low melting metallic binder, have already been produced by selective laser sintering. Powder combinations reported in literature involve $\mathrm{Fe}\left(1540^{\circ} \mathrm{C}\right)-\mathrm{Sn}\left(232^{\circ} \mathrm{C}\right)$, $\mathrm{Fe}\left(1540^{\circ} \mathrm{C}\right)-\mathrm{Cu}\left(1083^{\circ} \mathrm{C}\right), \mathrm{Cu}-\mathrm{Sn}, \mathrm{Cu}-\mathrm{solder}\left(7 \mathrm{OPb}-30 \mathrm{Sn}, 262^{\circ} \mathrm{C}\right)$, $\mathrm{Ni}\left(1455^{\circ} \mathrm{C}\right)$-Bronze $\left(1005^{\circ} \mathrm{C}\right), \quad \mathrm{Ni}-\mathrm{Sn}, \quad W \mathrm{~W}\left(2867^{\circ} \mathrm{C}\right)-\mathrm{Co}\left(1495^{\circ} \mathrm{C}\right)$, etc. $[13,56,57,87]$. WC-Co composites were produced at MIT by 3D printing WC powder with droplets of an organic binder. After the binder was burned out, the remaining porosity was impregnated with cobalt [77].

- CERMETs or metal matrix ceramic composites (which normally also include WC-Co ceramics) could also be produced rather easily by selective laser sintering, fused deposition modelling or 3D printing [57].

- Polymer matrix ceramic or metal composites can be produced by $3 D$ printing, selective laser sintering of polymer coated metal or ceramic powder, stereo-lithography or fused deposition modelling. The polymer matrix may be either permanent (i.e. remains in the final composite) $[47,88]$, or may be used only to form an intermediate 'green' part that will be post-treated to eliminate the polymer binder and to yield plain metallic or ceramic components $[2,28,32,34,79,80]$.

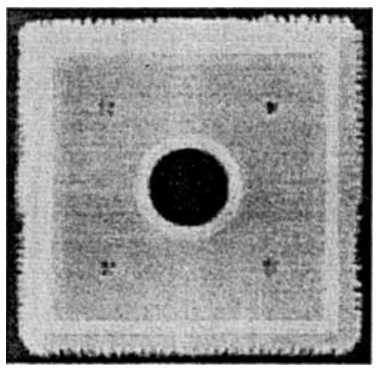

Fig. 6: Long fibre reinforced SL part (K.U.Leuven)

Besides composites, many additive manufacturing processes also allow production of multi-material parts, with for instance a soft core and hard skin [65]. Different processes, like Sander's Ink Jet Printing or Stratasys' Fused Deposition Modeling, are provided with two material printing or extrusion heads. Today those two material supplying heads are generally used, one to feed the part's material, the other to deposit support material (often wax) around the part or in the part's cavities, in order to support and protect the part during production. However, those processes are easily extendable to deposit different part materials in different zones. Multi-colour parts can be produced today by using appropriate colourable photopolymers with a patented stereo-lithography process $[92,104]$. Varying the laser energy allows selective colouring of certain areas of the part, like the bone tumour in the stereo-lithography model of the skull represented in fig. 7 .

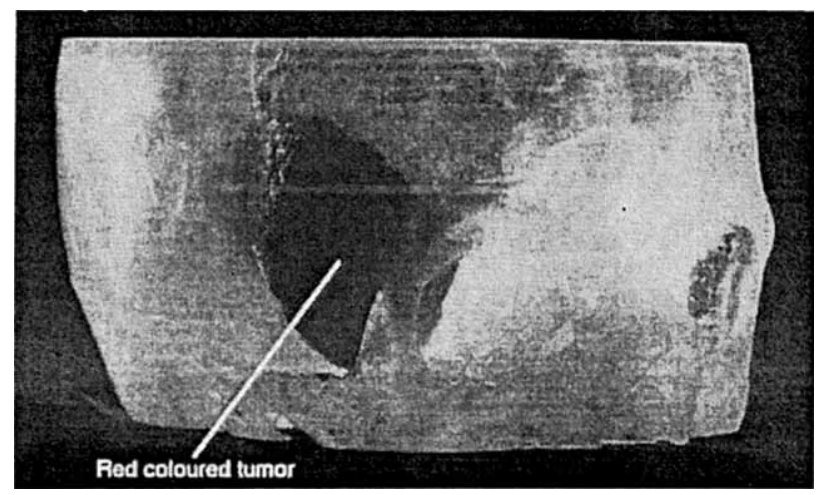

Fig. 7: Coloured stereo-lithography model of human skull 
Sharp transitions in multi-material parts yield problems of internal stresses, crack formation or delamination at the interface between different materials. To avoid such problems, Prinz has developed additive manufacturing techniques allowing to produce gradual transitions between different deposited materials [19]. Fig. 8 shows an example of such smooth transition from $316 \mathrm{~L}$ stainless steel to Invar produced with a laser cladding RP device provided with three different powder feeders (for 316L, Invar and copper support material)

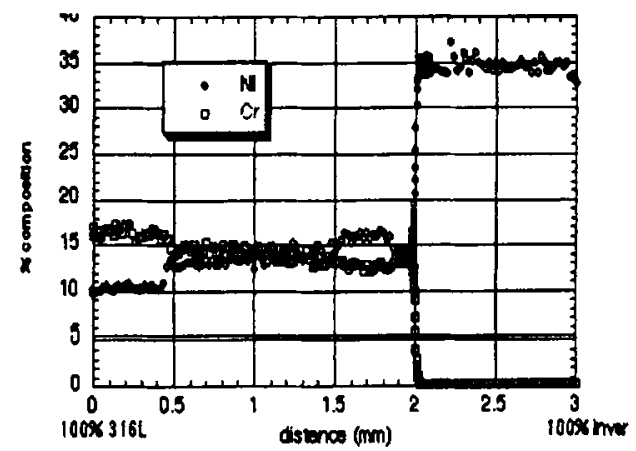

a. Sharo transition over $1.5 \mathrm{~mm}$ (1 laser track)

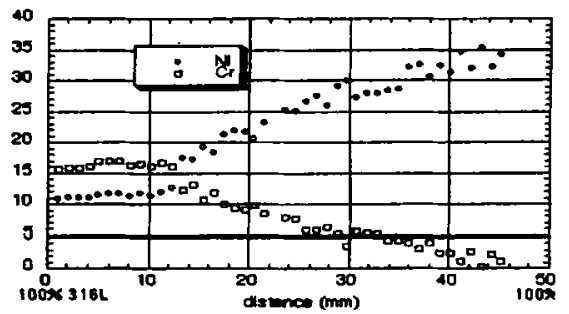

b. Gradual transition over $50 \mathrm{~mm}$

Fig. 8: Gradient from stainless steel to Invar (Stanford)

\subsection{Layer deposition}

Layer creation is a delicate and time consuming step in all layer-based rapid prototyping processes. Great difficulties are encountered in most processes to achieve accurate deposition of the layered base material. This deposition is often the clue to a successful or failing process. Therefore, quite some research focuses on new layer deposition systems for various types of bulk material used in RP processes (see table 3): i.e. liquid (see details in $\$ 4$ on SL), powder material (see details in $\S 8$ on SLS) and solid sheets (see $\$ 10$ on LOM). Techniques that have been used or tested include: dipping (liquid), scraping/rolling (liquid and powder), casting (liquid) [59], spraying (powder), electro-static deposition (powder and solid sheets) [4], pressing pre-formed sheet or foils (solids and solid/iquid). An example of the latter is the extrusion of green ceramic foils (made from ceramic and liquid photo-polymer resin) that are fed into a stereolithography device for further laser curing [72].

\subsection{Advanced laser technology}

Lasers play an important role in rapid prototyping and its development. From the eleven commercially available stereo-lithography or photocuring processes in 1997, ten apply laser energy to induce polymerisation. Only one vendor (Cubital) preferred to use flash lamps and masks. This allows a newly deposited resin layer to be illuminated at once, rather than being progressively scanred by a laser beam. However, this advantage has to be evaluated against the cumbersome need to produce an opaque mask reproducing the geometry of each individual layer. Two Japanese manufacturers produce machines applying a UV lamp and a fibre to induce polymerisation.

If we look to the whole range of rapid prototyping processes, we may state that more than half of those processes apply lasers: e.g. laser photo-polymerisation (stereo-lithography,...), laser fusion or sintering
(SLS), laser cladding (Laser Generating, Controlled Metal Build-up or CMB, Laser Aided Powder Solidification with powder Jet or LAPS-J, LENS,...), laser cutting (LOM,...), laser-induced CVD (SALD, LCVD). In sales volume, 1170 out of the 1499 RP machines sold until 1995 were laser-based, i.e. $78 \%$. The type of laser and the laser power used vary in a wide range: from $\mathrm{HeCd}$ lasers of some $10 \mathrm{~mW}$, along Ar-ion lasers of $100 \mathrm{~mW}$ to $1 \mathrm{~W}, \mathrm{CO}_{2}$ lasers of $50 \mathrm{~W}$ to well over $1 \mathrm{~kW}$, Nd:YAG lasers from below $1 \mathrm{~W}$ to $1.5 \mathrm{~kW}$ operated in pulsed or continuous mode. Diode lasers and frequency converted lasers also made their appearance in rapid prototyping, as will be detailed below $[5,75]$.

\subsection{Software support and CIM}

The efficiency of rapid prototyping and manufacturing owes a lot to the availability of performant software tools. A lot of CAD/CAM software has been developed and is now available to automate the whole work preparation $[41,49,60,85,91,102]$ : automatic verification and error fixing of CAD and STL files, automatic selection of optimal part orientation, adaptive slicing algorithms (layer thickness is adapted to the part's slant and curvalure in Z direction) [73,93], automatic generation of support structures under part overhangs [91], part merging and part splitting to fit workspace of machine, etc. Other software is available for on-line control and optimisation of the production process: on-line slicing, adaptive laser scanning software, etc. Quite some R\&D deals with software for simulating the physical processes involved $[8,18,42]$ : i.e. laser energy absorption (see CIRP STC-E working group), polymerisation or sintering process, shrinkage, distortion. Such software might be used in the future to select optimal working parameters for higher part quality, part accuracy and processing speed. A lot of software has also become available for special applications: production of rapid tools, medical applications [92], stress or FEM analysis [11], 3D faxing (Reverse Engineering, Data transfer and RP re-production of 3D models) [69], etc.

\subsection{New applications}

Another major trend characterising the first decade of additive manufacturing is the advent of new applications.

\section{a. Functional Prototypes}

Better materials have enlarged the scope of prototypes that can be produced by additive manufacturing techniques from visual or look-at prototypes to more functional prototypes. The latter prototypes may reproduce functions that require strength (like snap lits, elastic hinges, impact load, elc.), even though their properties do not fully equalise those of the real products that will be produced in a different way. Today, limited accuracy of rapid prototypes may be a greater handicap than strength.

\section{b. Concept modelling}

Several types of RP machines are well suited for operation in a CAD office. They are relatively small (desk-top devices), cheap and clean (no liquid or powder material, no need for messy post-processing). Special efforts have been made to increase speed at the expense of quality (e.g. surface roughness, accuracy, material strength). Those machines are called 'concept modellers', because they are mainly used for rapid check of the geometry of initial CAD design concepts. They are provided with software that tends to the simplicity of operation of a desk-top printer (i.e. just sending a file to a printing queue), although some pre-processing (support definition, STL triangulation, etc.) and post-processing (support removal) is often still required. Several of those 'concept modelling' machines will be described below: see FDM, IJP, 3DP, LOM processes.

\section{c. Functional parts and rapid tooling}

Today, improved material properties also allow producing functional parts. The most striking applications of functional parts produced by 
material addition processes are to be found in tool making, where they allow to reduce drastically the delay to produce moulds and dies. Those applications are hence denoted as 'Rapid Tooling'. Rapid tooling may be achieved through direct methods (i.e. mould components are directly produced by additive manufacturing) or by indirect methods (i.e. a master model is first produced by additive manufacturing and is used to produce the mould by some positive or negative reproduction technique, like casting) [55]. As an example of the direct rapid tooling techniques, which are of interest for this paper, fig. 9 shows two plastic injection moulds produced resp. by selective laser sintering of steel powder and by laminated object manufacturing using laser cut steel plates [16]. The latter process is also becoming popular for producing sheet metal bending punches [22] and forming tools [33].

\begin{tabular}{|l|c|l|}
\hline Polymer coated steel powder & Bulk material & 1100 laser cut steel sheets \\
\hline Copper infiltration & Post-process & EDM of drafts $\perp$ to sheets \\
\hline Possibly $>50.000$ shots & Life time & $>500$ shots in glass filled PA \\
\hline
\end{tabular}
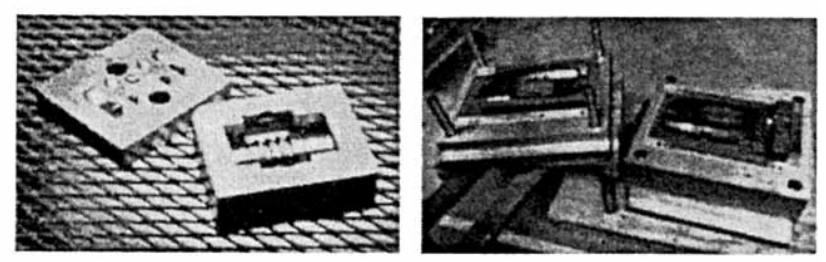

a. Selective laser sintering (EOS) b. Laminated Laser Cut Cavity (CRIF)

Fig. 9: Injection moulds produced by additive manufacturing

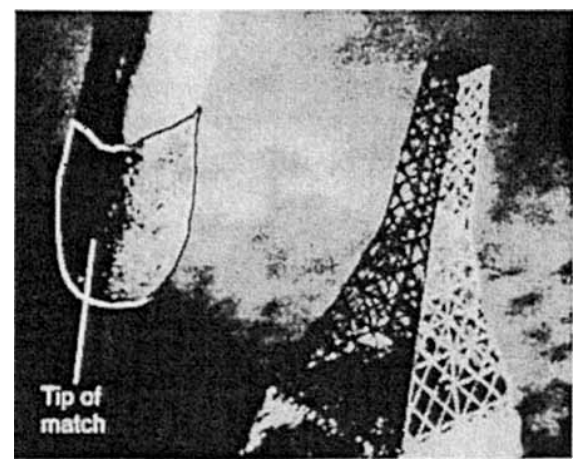

Fig. 10 : Aluminium micro tower made by laser induced CVD of Altrihydride gas (Max Planck Inst.)

\section{d. $\quad \mu$-machining}

Several RP processes lend themselves well for production of micro-parts. Those applications are still at research level $[3,10,36,103,106]$, but results are impressive. Fig. 10 and 15, resp., show examples of micro parts produced by laser-induced CVD and stereolithography.

\section{e. Medical models}

One of the most popular applications of rapid prototyping and additive manufacturing for other purposes than industrial design and manufacturing, undoubtedly is in the medical context: pre-operative medical models, prostheses, etc. Special software allows to use data from medical $C T$ scanners to build up a CAD, STL, SLI or CLI model or file (i.e. Reverse
Engineering) suited for the production of a physical model (Rapid Prototyping): see coloured skull model in Fig. 7 [92].

\section{Stereo-Lithography (SL)}

Stereo-Lithography (SL), that creates parts by 'laser-curing' successive layers of liquid resin (Table 3), was the first system commercially available and hence counts more installed units than any other process. However, the yearly unit sales of other systems are catching up (Table 2). Throughout the past decade, twelve companies offered commercial SL equipment, but some merges and failures brought back their number to nine (Table 3 ).

New types of lasers have entered the scene of SL. He-Cd lasers (output power up to $40 \mathrm{~mW}$ at the wavelength of $325 \mathrm{~nm}$ ) are now often replaced by higher power Argon-ion lasers, with an output power up to $600 \mathrm{~mW}$ at $351 \mathrm{~nm}$. Solid state and diode lasers are also applied [75]. Unfortunately, diode lasers are not yet available at the ultraviolet wavelengths needed for most SL resins. However, they are used to pump solid state lasers in order to achieve UV wavelengths. Although these laser systems are rather complicated and more expensive, they can be more reliable and efficient than the gas laser technology most commonly used in SL. In addition, diode pumped solid state lasers for UV can be made much smaller than the gas lasers with the same power level. Frequency converted UV diode pumped solid state lasers are commercially available in many different forms: frequency tripling of the powertul lines of Nd:YAG, Nd:YVO, and Nd:YLF lasers results in wavelengths of $355 \mathrm{~nm}$ (Nd:YAG and Nd:YVO,), $351 \mathrm{~nm}(\mathrm{Nd:YLF)}$, and $349 \mathrm{~nm}$ (Nd:YLF).

With those high-power UV-lasers, the processing speed is no longer limiled by the laser power, but by the maximum scanning speed of the scanner. Therefore, developments are underway to apply continuous rotating hexagonal mirrors instead of oscillating galvano mirrors for scanning the laser beam over the liquid surface [72], or to apply multioptical-fibre illumination systems [63].

Since resin re-coating is another time consuming step (sometimes over $50 \%$ of total production time), considerable efforts have been spent to accelerate the process of adding a new liquid layer on top of the SL building vat and to improve the accuracy of layer deposition and layer thickness control. Several companies are searching for alternatives to the original scraper blade re-coating mechanism that

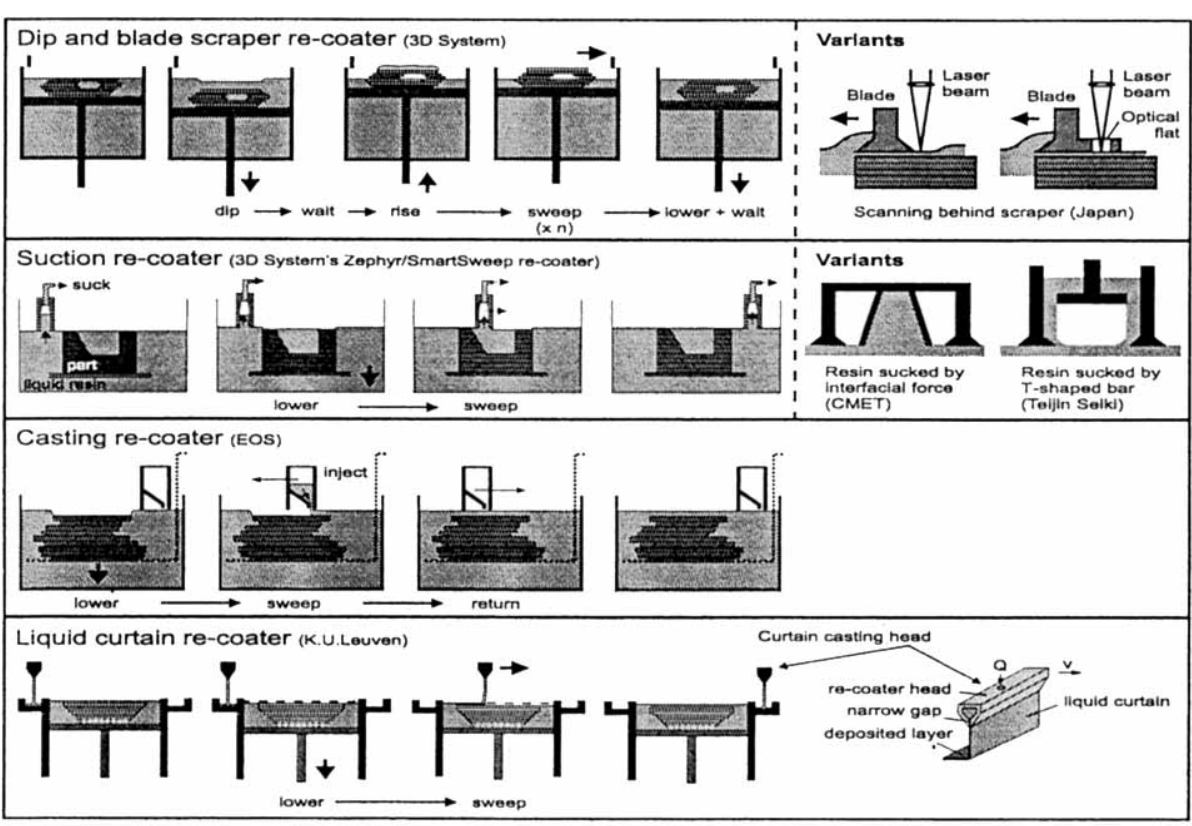

Fig. 11: Re-coating systems for stereo-lithography. 
should also eliminate problems in re-coating trapped volumes (Fig. 11). Nakagawa [72] describes two alternative scraper blade systems in which the laser scans the liquid surface directly behind the scraper blade, at a place where the layer thickness is properly defined. Those systems allow to eliminate multi-pass scraping and additional waiting to allow for further levelling of the viscous resin. 3D Systems has introduced a Zephyr and SmartSweep re-coater that apply a sucking scraper. EOS uses a casting scraper head. Since these mechanisms force the flow of the resin, differences between solid or liquid substrate and trapped liquid volumes yield less problems. However, as contact between re-coating mechanism and liquid surface remains, these problems are not totally eliminated, while the re-coater sweep rate has to be limited to avoid high shearing forces that may damage or destroy the part under construction.

The University of Leuven and Materialise have patented a new recoating mechanism, called the liquid curtain re-coating mechanism $[53,59]$. By making the liquid SL resin flow through a narrow slot of an elevated pouring head, a liquid curtain is formed that drops under gravitational acceleration. A liquid layer is deposited by moving the head and liquid curtain over the workpiece. By controlling the flow rate and the velocity of the pouring head, a layer of required thickness is deposited in only a couple of seconds (about $2 \mathrm{sec}$ ). In comparison to a scraper system that needs on average 0.5 minute to deposit a liquid layer, this curtain coating mechanism can save a lot of time (E.g. 240 $\mathrm{mm}$ high part with $0.1 \mathrm{~mm}$ layers means some 2400 layers $\times 0.5 \mathrm{~min}$ or 20 hours saving). Since the liquid curtain drops from a certain height, contact between pouring head and top surface in the vat is totally eliminated and no shear forces are applied to the part. Hence, support structures can be weaker and are removed more easily with less danger to damage the part.

Instead of laser scanning the top free liquid layer, Mitsui and Denken opted for illuminating the lower liquid surface through a glass plate positioned in the bottom of the SL building vat: Fig. 12a $[51,72]$. This glass plate allows an accurate control of the flatness and thickness of the applied liquid layer.

Recently, a system has been proposed that polymerises the liquid inside the liquid vat rather than at the top surface by forming an air bubble at the end of a pipe dipped into the resin: Fig. 12b $[64,72]$. An UV-laser beam penetrates through the pipe into the resin and solidifies it on the bubble. This system completely eliminates the need for successive liquid layer deposition and allows to polymerise very thin layers, but limits the scanning speed.

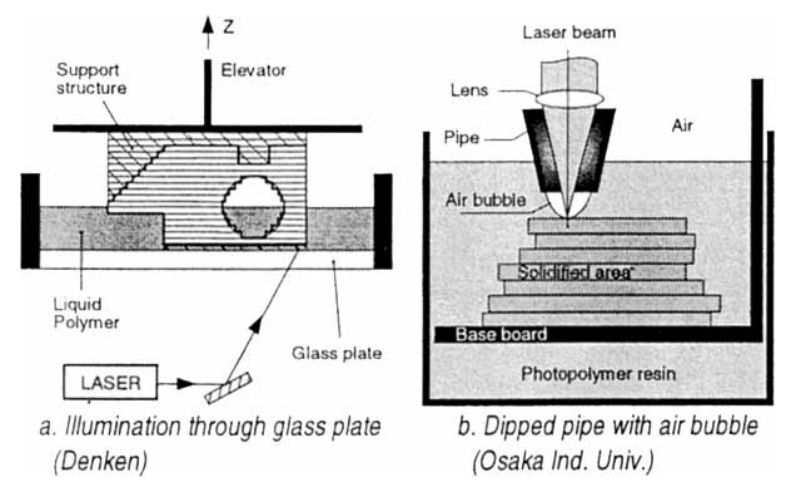

Fig. 12: SL layer thickness control: no free liquid surface

Further speed increases, resp. accuracy improvements, have been obtained by developing appropriate laser scanning patterns (called hatching patterns or build styles) for various applications. Examples are $[25,30]$ :

- Star-Weave: spaced hatch lines with unpolymerised resin in between (to be polymerised in UV post-processing oven) and aiming fast production without too much distortion (hatch lines only connected to the part's contour at one end).

- QuickCast, TetraCast: drainable honeycomb structure for building investment casting patterns that will collapse during pattern burn out and avoid cracking the ceramic shell.

- ACES (Accurate Clear Epoxy Solid): dense hatching pattern with some $40 \%$ overlap between scan tracks that results in accurate green parts containing no more liquid resin and free of intemal stresses (part distorsion).

Stereo-lithography requires support structures to be constructed underneath the part. Those struclures are needed to hold various parts of the product connected to each other, or to the building plattorm, and to support weak overhanging parts of the product during layer building.

The support structures used in SL are normally composed of a grid of plain vertical walls. Producing those plain walls may require an important amount of material and time. To overcome this, 'perforated supports' have been conceived (Fig. 13). They depict perforations in the walls and result in a beam-like support structure that has about the same strength as plain wall supports, but requires much less material to be cured (reduced material cost and building time/cost) and are much easier to be removed afterwards (reduced post-processing time/cost) [92].

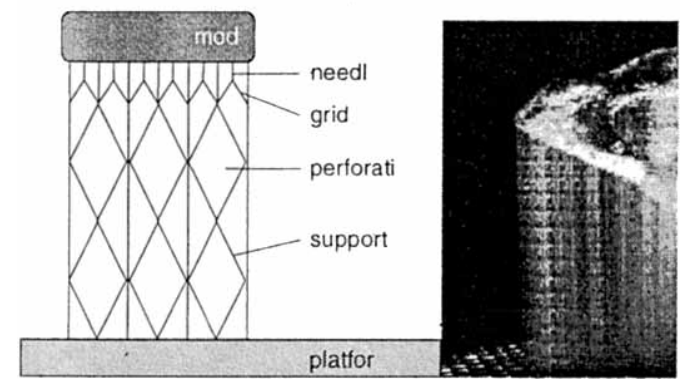

Fig. 13: Perforated support (Materialise)

The University of Tokyo developed a system that avoids the need to build support structures in stereo-lithography $[70,72]$. The liquid resin surrounding the part being built is cooled and frozen in order to act as solid support for further layers (Fig. 14). This process applies a special $\mathrm{SL}$ photo-polymer that is sufficiently fluent when heated at $95^{\circ} \mathrm{C}$ in order to be deposited by a special heated nozzle, while it freezes when cooled down to $5^{\circ} \mathrm{C}$. The machine should also be equipped with appropriate temperature control: highly conductive cooled bottom elevator platform, cooling coil around building vat, possible supply of liquid nitrogen above vat, temperature sensors, etc.

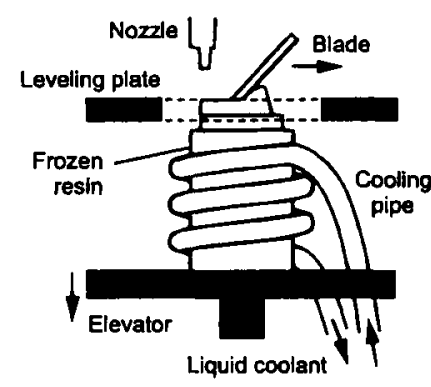

Fig. 14: Supportless SL using frozen resin.(Univ. Tokyo)

Frozen support structures are also used in the Rapid Freezing Prototyping process investigated at the New Jersey Institute of Technology and Tsinghua University [105]. This process applies frozen water as part build material and frozen brine to build support structures where needed. The lower freezing point of brine allows 
removal of the support without destroying the frozen part that may be used as ice pattern in silicone moulding or investment casting.

Several researchers have developed special $\mu S L$ devices for the production of micro-stereo-lithography parts $[3,36,103,106]$. The Kyushu Institute of Technology succeeded to reduce the polymerisation voxel size to $5 \times 5 \times 3 \mu \mathrm{m}$ (i.e. the size of the smallest polymerisable volume). Examples shown include a $80 \mu \mathrm{m}$ one-way venous valve for medical applications and a helical spring of $50 \mu \mathrm{m}$ outer diameter,

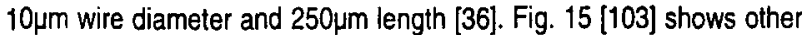
examples.

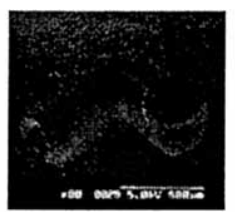

a. Micro SL pipe

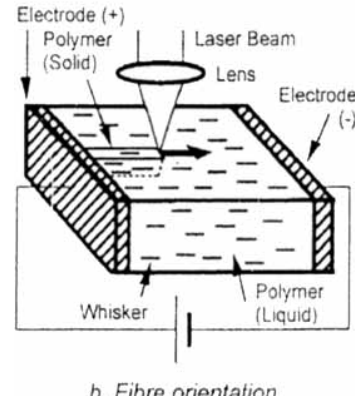

ibre orientation

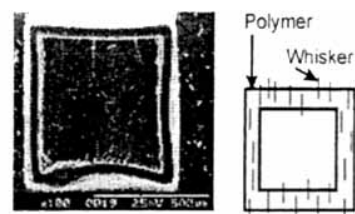

c. Constant orientation

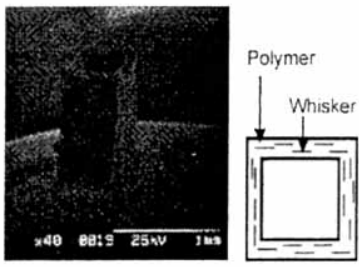

d. Variable orientation
Fig. 15: Micro-stereo-lithography of whisker reinforced microstructures

Another recent evolution is 'colour stereo-lithography' developed in co-operation between Zeneca (resin provider), Materialise (software provider) and K.U.Leuven (provider of prototype SL-machine) [92,104]. This process uses a (clear) liquid resin containing additives that colours red or blue upon exposure to a high dose of UV light: Fig. 16. Each layer of the model is cured in the usual way, using a dose of UV light sufficient for hardening but not for colouring. When the layer is completed the laser re-scans the area required to be coloured at a lower speed, so delivering a much higher UV dose.
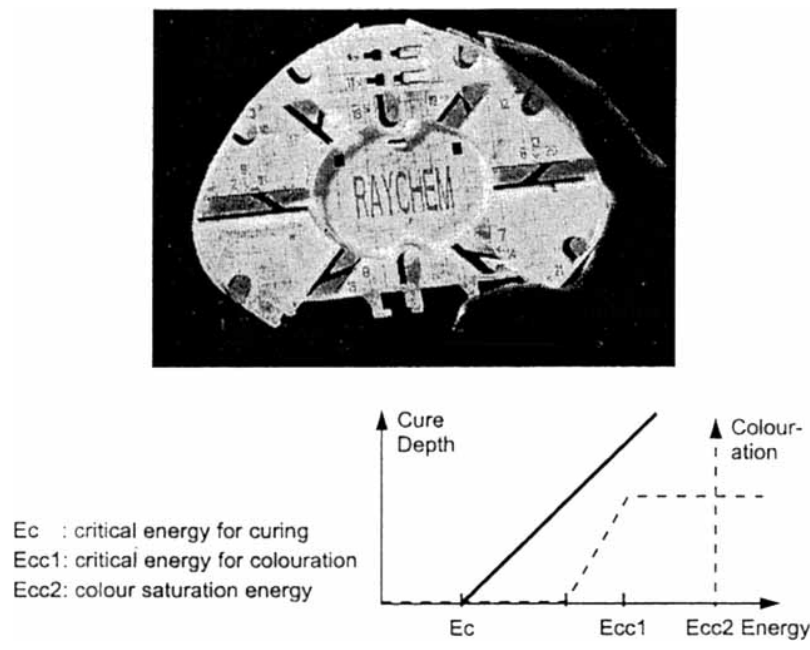

Fig. 16: Colour stereo-lithography

The process is repeated layer by layer to build up the model containing coloured regions. The most important application is situated in the field of medical models: e.g. skull tumours can be coloured, allowing much better visualisation than with conventionai transparent or opaque models (Fig. 7). On technical parts, colour may be used to show changes in design iterations of new products, highlighting differences in stress or flow within a part, labelling, etc.

Materials for stereo-lithography are hardened by photopolymerisation. This limits the choice in materials. Nevertheless, major progresses have been achieved in the development of new photopolymers depicting higher curing rates, less shrinkage during curing (higher accuracy, less part distortion), better mechanical and thermal strength, etc. $[38,68,86,89,94,95]$.

Today, most commercial SL resins are epoxies. Compared to the acrylic based resins of early times these epoxies show very low shrinkage $(2-3 \%$ volumetric shrink compared to $5-7 \%$ for acrylates [38]. They also have better mechanical and thermal properties. As an example, table 4 compares the properties of a DuPont SOMOS 3100 acrylate and a SOMOS 6100 epoxy resin [68]. The epoxy scores better except for the higher energy required for photo-polymerisation. The latter may slow down the polymerisation process of epoxies as compared to acrylates, for identical laser power. However, highly reactive epoxies are becoming available too.

Table 4: Comparison of acrylate and epoxy SL resin.

\begin{tabular}{|c|c|c|}
\hline & $\begin{array}{c}\text { Somos } 3100 \\
\text { acrylate }\end{array}$ & $\begin{array}{c}\text { Somos } 6100 \\
\text { epoxy }\end{array}$ \\
\hline ACCURACY & $\cdot$ & + \\
\hline Volumetric shrink (\%) & $5-7 \%$ & $2-3 \%$ \\
\hline MECHANICAL PROPERTIES & - & + \\
\hline Tensile modulus (MPa) & $1083 \mathrm{MPa}$ & $3222 \mathrm{MPa}$ \\
\hline Tensile strength (MPa) & $24.2 \mathrm{MPa}$ & $58.3 \mathrm{MPa}$ \\
\hline Hardness (Shore D durometer) & 84.6 & 86.7 \\
\hline Notched lzod Impact Strength (J/m) & $65.4 \mathrm{~J} / \mathrm{m}$ & $42.3 \mathrm{~J} / \mathrm{m}$ \\
\hline Flexural strength (MPa) & $23 \mathrm{MPa}$ & $103 \mathrm{MPa}$ \\
\hline THERMAL PROPERTIES & $\cdot$ & + \\
\hline Heat Deflection Temp. $\left({ }^{\circ} \mathrm{C}\right)$ & $47.5^{\circ} \mathrm{C}$ & $55^{\circ} \mathrm{C}$ \\
\hline PRODUCTION SPEED & + & - \\
\hline Required critical energy (E) & $4 \mathrm{~mJ} / \mathrm{cm}^{2}$ & $26 \mathrm{~mJ} / \mathrm{cm}^{2}$ \\
\hline
\end{tabular}

A new development of 3D Systems, called 'Direct AIM' ${ }^{\text {TM1 }}$ (AIM = ACES Injection Moulding) results in SL parts having sufficient mechanical and thermal strength to allow inserts of injection moulds to be produced directly in SL resin material $[37,55]$. This process applies an epoxy resin (Cibatool SL 5170) and a special build style or laser scanning pattern, called ACES (see above), ensuring high accuracy and minimal residual stresses. Such SL insert has a glass transition temperature of about $75^{\circ} \mathrm{C}$ and allow to inject 20 to 100 thermoplastic parts at up to $300^{\circ} \mathrm{C}$, under proper cooling conditions: table 5 .

Table 5: Injection parameters used with AIM moulds

\begin{tabular}{|l|l|l|l|l|l|}
\hline Parameter । Material & LDPE & HDPE & PS & PP & ABS \\
\hline Injection Pressure (bar) & 110 & 160 & 170 & 130 & 220 \\
\hline Injection Temp. $\left({ }^{\circ} \mathrm{C}\right.$ ) & 180 & 220 & 200 & 205 & 240 \\
\hline Cycle Time (minutes) & 3.5 & 4.5 & 4.0 & 4.0 & 5.0 \\
\hline
\end{tabular}

The University of Dayton developed a family of diacrylate resins that contain rigid rod-shaped molecular segments [81]. Those resins could be applied in two ways:

- When polymerised in an unordered anisotropic way, those rigidrod molecular structures may raise the glass transition temperature to over $150^{\circ} \mathrm{C}$.

- When using a magnetic field (from orientable magnets put around the polymerisation val of the SL machine), one can impose a fixed orientation to the rigid molecular segments of the monomer that contain a liquid crystal phase. The resulting anisotropy may yield interesting material properties in term of strength, thermal expansion (negative coefficient parallel to alignment) and low polymerisation shrinkage (close to zero). 
Mechanical and thermal properties can also be improved by mixing neutral fibres or particles, like glass or carbon fibres, to the photopolymer [26,76]. Fig. 17 shows a fracture surface of a SL resin reinforced with small spherical glass particles. The University of Nagoya applies a magnetic field to orient TiC whiskers $(01 \mu \mathrm{m}, 20$ $70 \mu \mathrm{m}$ long) in the liquid resin prior to polymerisation [103].

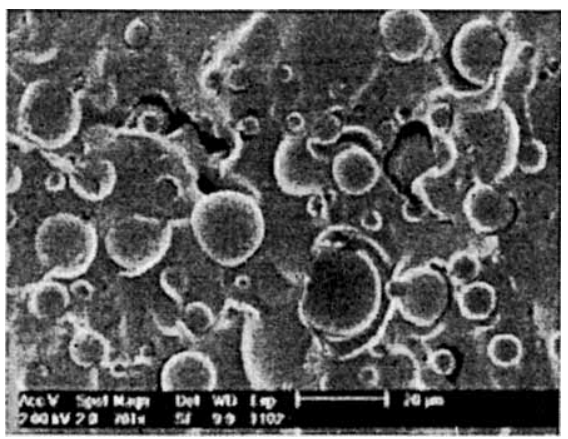

Fig. 17: Fracture surface of resin filled with spherical glass particles. (K.U. Leuven)

The production of pure ceramic parts is possible by creating ceramic green bodies by photo-polymerising a ceramic slip consisting of about 50 vol\% ceramic powder dispersed within a UV curable polymer $[28,32,34,57]$. Afterwards the green part is heated to $250-500^{\circ} \mathrm{C}$ to burn-out the polymer binder, followed by high temperature sintering $\left( \pm 1600^{\circ} \mathrm{C}\right)$ to produce a strong pore-free ceramic $(96 \%$ density). Such $S L$ process has been used for producing parts in alumina $\left(\mathrm{Al}_{2} \mathrm{O}_{3}\right)$, sillicon nitride $\left(\mathrm{Si}_{3} \mathrm{~N}_{4}\right)$ and silica $\left(\mathrm{SiO}_{2}\right)$ : Fig. 18 [28]. To avoid problems in re-coating the highly viscous ceramic slurry with a scraper blade, Japanese researchers developed a process in which the ceramic slurry is pre-laminated into semi-solid foils that are conveyed to the SL machine where they are pressed onto the previous cured layers [32]
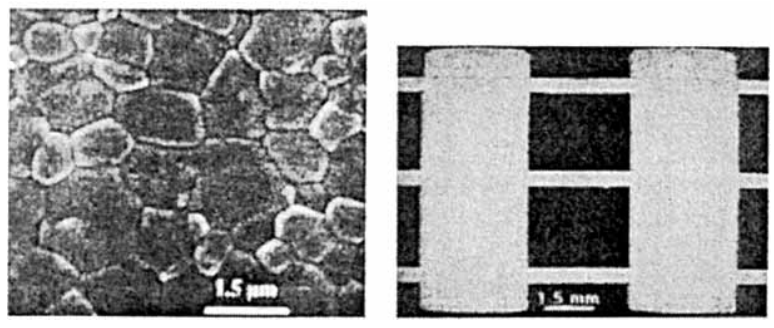

Fig. 18: Micro ceramic parts produced with stereo-lithography (Univ. Michigan)

\section{Fused Deposition Modelling (FDM)}

Fused Deposition Modelling (FDM) has grown to one of the most popular RP processes. In 1996 the unit sales of Stratasys FDM machines even surpassed those of 3D Systems' SLA machines.

FDM builds parts by depositing a stream of hol viscous material onto a base plate or previously deposited material [12] : see Table 3 . Solidification of the molten material is obtained by natural cooling of this material; so theoretically any thermoplastic or heat fusible material can be used. If necessary a support in a different material (e.g. wax) is built to support wide overhanging parts.

Build speed of industrial FDM equipment (Stralasys) has been increased by up $10500 \%$ by applying a new patented two-axis high speed motion control system (see Fig. 19) that moves each of the two extrusion heads for part and support material independently [9]. Each extrusion head hangs with air cushions and electro-magnets directly to a common $X Y$ platform. The electro-magnetic unit in such head also acts as two linear stepper motors 10 move the head in $X$ and $Y$. Such system eliminates the masses and inertia of classical superposed $X$ and $Y$ guideways and drives, hence allowing high accelerations, high speeds (up to $254 \mathrm{~mm} / \mathrm{s}$ instead of $38 \mathrm{~mm} / \mathrm{s}$ while extruding, $508 \mathrm{~mm} / \mathrm{s}$ for repositioning) and an accuracy of $\pm 1 \mu \mathrm{m} / \mathrm{mm}$.

A similar fused polymer material extrusion process forms the basis of the low-price Genisys desk-top machine from Stratasys, which is based on an earlier IBM development. This machine uses a more traditional table and gantry axis configuration moving the single extrusion head (Wall-like supports and part are made from same material). Wafers of a wax-like polyester compound are fed from a feeder cassette (no wire coil as in FDM) into a pressurised heating device and an extrusion pump.

Part quality and accuracy have improved by more intelligent toolpath generation software, build strategies and machine control software avoiding or remedying to overlaps and gaps between adjacent streams of extruded material [39]. A study investigated the influence of the build styles on the mechanical properties of FDM parts and proved the benefit of post-infiltration of adhesive to improve those properties [21].

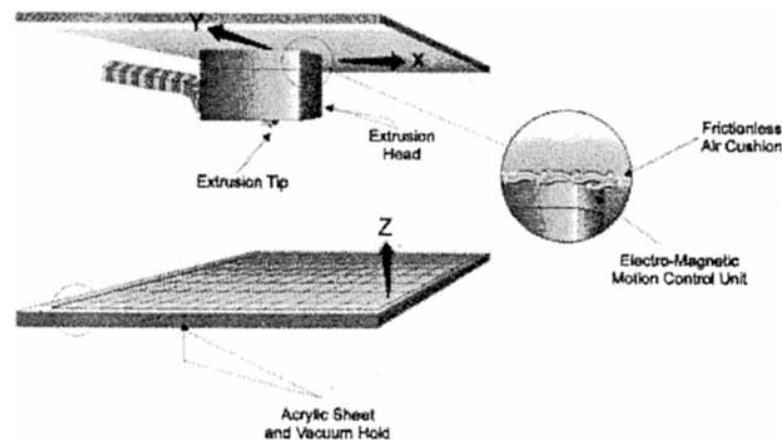

Fig. 19: Stratasys MagnaDrive System (Only one head shown)

In 1991 three thermoplastic materials were available for FDM part building [51]: investment casting wax, wax-filled plastic adhesive material (machinable wax) and Nylon.

Most important may be that Nylon has been replaced by ABS after 1994: simple white or coloured, or medical grade ABS. Elastomers are also available.

Research is going on to include ceramics and metals to the list of materials. A Multiphase Jet Solidification process (MJS), very similar to $\mathrm{FDM}_{1}$ has been developed at the German Fraunhofer institutes IFAM and IPA to extrude other materials than just thermoplastics [99]. Early experiments to extrude very low melting point metal alloys (tinbismuth with $\mathrm{Tm}$ between $70^{\circ}$ and $180^{\circ}$ depending on composition) without any polymer binder, yielded some problems due to the low viscosity and the surface tension of the molten metal. Hence accuracy and shape complexity were limited. Today, research focuses on extrusion of mixtures of 50 vol\% stainless steel powder with a polymer binder (EVA co-polymer and paraffin wax) that is burned out afterwards, before post-sintering the metal (18\% shrink). Fig. 20 shows some results.

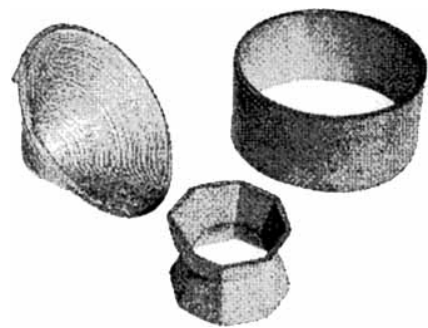

Fig. 20: Stainless steel parts made by Multiphase Jet Solidification (IFAM/IPA) [27] 
FDC (Fused Deposition of Ceramics) uses polymer or wax filaments filled with ceramic particles $[2,80]$. After building the part in a standard FDM machine, the binder is burned out and the part is post-sintered. The materials tested so far are:

\section{- $\mathrm{Si}_{3} \mathrm{~N}_{4}$ Silicon nitride}

- Fused silica

- Piezo active material (PZT- lead zirconium titanate)

- Tungsten carbide cobalt

- Alumina

IFAM/PA also tested polymer bound materials of titanium, bronze, silicon carbide and alumina on their MJS machine. The Swinburne University, Australia, developed an iron-nylon composite filaments intended for direct FDM production of metal/polymer composite injection moulds [88].

\section{Ink Jet Printing (IJP)}

Ink Jet Printing (IJP) has been another booming AP technology in the past years. Despite the recent failure of the first IJP machine developer (BPM Technology, ex. Perception Systems, with its Ballistic Particle Manufacturing machine), another company has reached the top three of RP vendors with its IJP machine (Sanders Prototype Inc. with Model Maker machines, see Table 3), while one of the two other top vendors also launched some IJP equipment (3D Systems' Actua machines). All those machines are based on the principle of accumulation of droplets of material shooted on-demand by piezoelectric ink-jet printing nozzles: Fig. 21 [23].

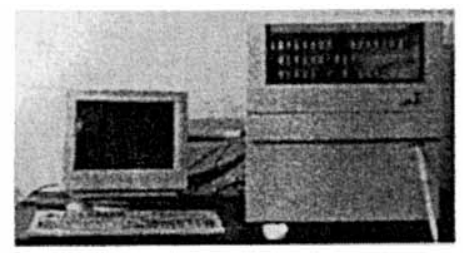

a. Machine

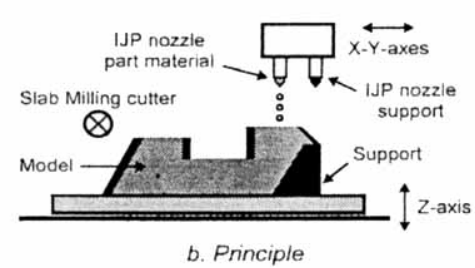

Fig. 21: Model Maker II Ink Jet Printing System (Sanders)

The recent success of IJP is due to the development of cheap, clean, desk-top like machines, often suited as 'concept modellers' (Stratasys' Genisys machine is often assimilated to this category of concept modellers, although it used continuous material extrusion instead of drop shooting).

High build velocities have been achieved on the Actua machine by working with a linear array of 96 jets (Although some companies still mention build times of $30 \mathrm{~h}$ for their average parts - RP\&M' 98 Cont. p 54). If needed, a quite dense support structure, made from the same material as the part, has to be built on this machine and manually removed atterwards.

The Model Maker machine is slower and hence less suited as concept modeller, because it has only one jet for the part material (polyester/plastisizer blend, $\operatorname{Tm} \square 90-113^{\circ} \mathrm{C}$ ) and one for depositing plain support material (wax compound, $\mathrm{Tm}=40-65^{\circ} \mathrm{C}$ ) [90]. This latter material is deposited all around and inside the part and is dissolved in solvent afterwards. The Model Maker accuracy is however better, mainly in the build direction (Z), because each layer is milled off after printing. This allows to work with layers down to $19 \mu \mathrm{m}$ and makes the process very suited for small, accurate and intricate parts, that are often used as lost wax models for investment casting: Fig. $21 \mathrm{~d}$.

Materials used for IJP are wax-like thermoplastic materials (see above). Their strength lies in between that of waxes and technical thermoplastics. Those materials are sufficient for the purpose of concept modelling, while also suited for investment casting models. Since IJP mainly aims at those applications, the pressure to develop other materials is rather low at this time.

\section{3D Printing (3DP)}

3D Printing is a process originally developed at MIT [78]. it uses solid powder material that is deposited in layers that are successively solidified by ink-jet printing droplets of binder onto the powder material: Fig. 22. Today, MIT has licensed the process to six companies, each one authorised to develop and commercialise it for different applications.
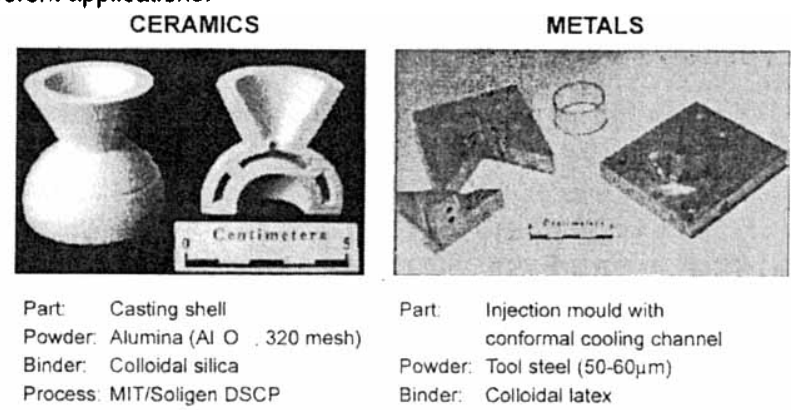

Part Injection mould with conformal cooling channel Powder: Tool steel $(50-60 \mu \mathrm{m})$ Binder: Colloidal latex Process: MIT/Extrude Hone

3D PRINTING PROCESS
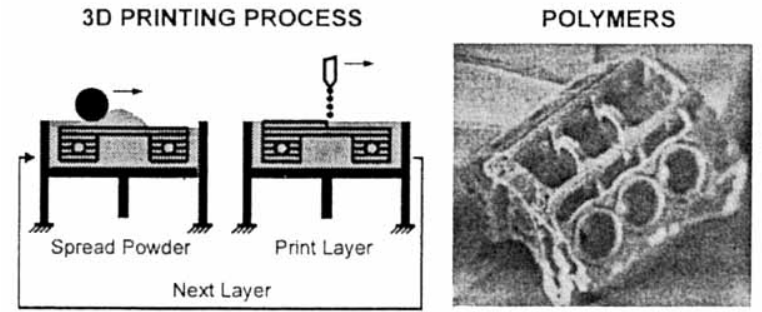

Part: Concept Model of motor block Powder: Starch-based polymer Binder: Starch activating solution Process: MIT/Z Corp. 3DP

Fig. 22: 3D Printing principle and materials

3DP has been used for many years to produce ceramic casting shells of aluminium oxide or aluminium silica powder and colloidal silica binder. Parts have to be post-processed in two steps: curing at $150^{\circ} \mathrm{C}$ and firing at $1000-1500^{\circ} \mathrm{C}$. This process is commercially available under the name 'Direct Shell Production Casting' (DSPC) from Soligen Inc. (for production of ceramic shells; no machine sales so lar).

Recently, the process also became commercially available to produce metal parts, mainly injection moulds, through Extrude Hone Corp. In this case stainless steel or tool steel powder of some $50-60 \mu \mathrm{m}$ is used with a colloidal latex binder to obtain a green part with typically $58 \%$ metal, $10 \%$ polymer binder and $32 \%$ pores. After furnace de-binding and pre-sintering to a density of approx. $63 \%$, the part is infiltrated to full density with a copper alloy during a second lurnace cycle at $1100^{\circ} \mathrm{C}[79]$.

In November 1997, Z Corporation launched a machine for printing polymer parts according to MIT's 3DP process. Speed is ensured by 125 jets that print droplets of a proprietary water-based solution onto a

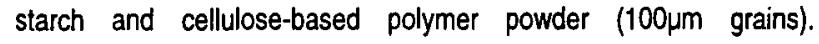
Whenever hit, the binder solution activates the starch, that glues the powder grains together. The resulting parts have limited strength and need a ten-minute infiltration by dipping into a bath of molten wax in order to ensure normal handling resistance. Dipping into a low viscosity two-part epoxy may yield greater durability. This process is 
very promising as a concept modeller, because of its very fast speed (the fastest RP process ever) and relative low cost

\section{Selective Laser Sintering (SLS)}

Selective laser sintering produces parts by fusing or sintering together successive layers of powder material. Novelties in this field are mainly related to lasers, optics, temperature control and materials. The Bayerisches Laser Zentrum in Germany developed a dual-beam system for laser sintering [24]. This dual-beam has a central high power beam for sintering and a surrounding low density beam for preheating the powder in order to reduce thermal stresses (Fig. 23). Some vendors offer SLS machines with an enlarged working area, resp. speed, by using two $\mathrm{CO}_{2}$ lasers, each with its own scanning head, working simultaneously on adjoining areas [84].

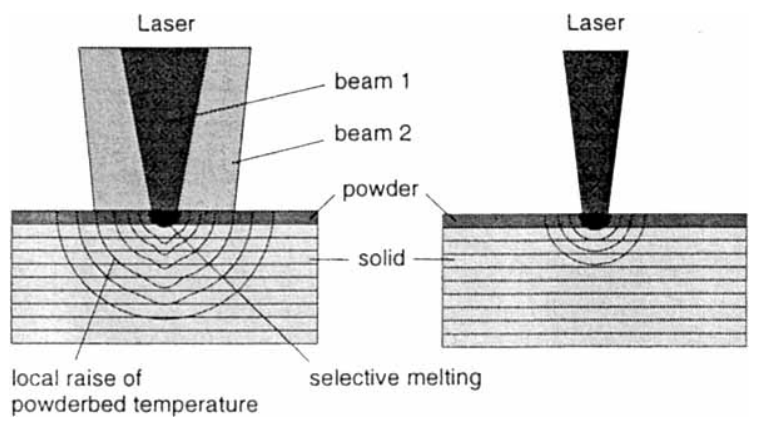

Fig. 23: Dual beam system for laser sintering (BLZ) [24]

Today, commercial machines all apply $\mathrm{CO}_{2}$ lasers (10.6um wavelength) ranging from 50 to $200 \mathrm{~W}$, but a trend towards the use of $1.06 \mu \mathrm{m} \mathrm{Nd:YAG} \mathrm{lasers} \mathrm{is} \mathrm{noticed,} \mathrm{at} \mathrm{least} \mathrm{for} \mathrm{sintering} \mathrm{metal} \mathrm{powder,}$ because of the better energy absorption of metals at shorter wavelength and the decreasing price of YAG lasers $[87,98]$. Diode lasers have been applied by UMIST to sinter $\mathrm{Cu} / \mathrm{Sn}$ powder $(60 \mathrm{~W} \mathrm{CW}$ laser operating at $810 \mathrm{~nm}$ ) and by ILT in Germany [5,62].

Different studies address the difficult problem of re-coating or deposition of regular thin powder layers [59]. Tests were done to apply an electrically charged photoreceptor plate to attract a thin powder layer and move it to the building area [4]. Most of those systems may equally be used in SLS, IJP and 3DP.

One of the strongest features of SLS is that it is able to process a very wide range of materials (standard polymers, metals, ceramics, foundry sand, etc.) in a direct way (i.e. sacrificial binder not mandatory), while yielding excellent material properties (i.e. close to those obtained with other manufacturing methods) [67].

Polymers are the original and still most applied materials.

Amorphous polymers, like polycarbonate powders, are able to produce parts with very good dimensional accuracy, feature resolution and surface finish (depending on the grain size), but they are only partially consolidated. As a consequence these parts are only useful for applications that do not require part strength and durability. Typical applications are SLS models for the manufacture of silicone rubber and cast epoxy moulds [67].

Semi-crystalline polymers, like nylons (polyamide), on the contrany can be sintered to fully dense parts with mechanical properties which approximate those of compression moulded parts. Still better part properties are obtained by using glass bead reinforced nylon powder [83]. On the other hand, the total SLS process shrinkage of these semi-crystalline polymers is typically $3-4 \%$ [29], which complicates production of accurate parts. The good mechanical properties of these nylon based parts make them particularly suited for high strength functional prototypes. New grades (i.e. DuraForm PA12 [82]) even yield resolutions and surface roughnesses close to that of polycarbonate $(\mathrm{PC})$, making polyamide $(\mathrm{PA})$ also suited for patterns for casting silicone rubber and epoxy moulds. Table 6 gives an overview of the mechanical properties of some SLS polymer materials (DTM). Other polymer-based materials available from the same company are acrylic styrene (PMMAPS) for investment casting and PA coated copper for plastic-metal composite injection moulds.

Table 6: Mechanical properties of some SLS polymer materials (DTM).

\begin{tabular}{|l|c|c|c|c|}
\hline & PC & PA.(Nylon) & Glass filied PA & Elastomer \\
\hline Tensile modulus (MPa) & 1200 & $1400 / 1800^{*}$ & $2800 / 4400^{*}$ & 20 \\
\hline Tensile strength (MPa) & 23 & $36 / 44^{*}$ & $49 / 42^{*}$ & - \\
\hline Break elongation $(\%)$ & 5 & $6 / 22^{\circ}$ & $1.8^{*}$ & 111 \\
\hline $\begin{array}{l}\text { Surface roughness R. } \\
\text { as processed }(\mu \mathrm{m})\end{array}$ & 7 & $12 / 8.5^{\circ}$ & 15 & $\cdot$ \\
\cline { 2 - 4 } & \multicolumn{2}{|c|}{ "value for DuraForm PA } & \\
\hline
\end{tabular}

Production of metallic parts by SLS is finding real industrial applications, mainly in tool making (Fig. 9). DTM has developed a proprietary process (RapidTool) that applies a polymer coated steel powder. The polymer melts and acts as a binder during laser sintering. During the post treatment, it is burned out and the porous 'green' part is infiltrated with bronze or copper [67].

EOS avoids the use of a sacrificial polymer binder by directly sintering a low melting point bronze-nickel metal powder, developed by the Swedish company Electrolux [6]. During sintering of this powder blend, metallographic transformations yield volumetric phase expansions that compensate the powder compaction due to sintering. This results in green parts with low net shrinkage, but over $20 \%$ porosity and low melting point $\left(\mathrm{Tm}=900^{\circ} \mathrm{C}\right)$ hampering further infiltration with e.g. $\mathrm{Cu}$ $\left(\mathrm{Tm}=1083^{\circ} \mathrm{C}\right)$. Therefore, these green parts are normally infiltrated with a high temperature epoxy resin that improves the bending strength to approximately $400 \mathrm{MPa}$ [100]

Several research institutes study direct laser sintering of high strength, high temperature metals without sacrificial polymer $[13,56,87]$. The agglomeration of the metal powder grains may rely on three basic binding mechanisms $[1,56]$ :

- Solid State Sintering (SSS) rely on solid state diffusion of atoms at the grain interfaces. This diffusion process however is too slow for sintering by rapid scanning with a laser beam.

- Liquid Phase Sintering (LPS) applies a mixture of two metals: a high melting point metal, called structural material, and a low melting point metal, called matrix. Heating the powder causes the matrix material to melt and to flow under capillary forces into the pores, formed by the non-molten structural particles. Since the matrix is a metal, it does not need to be removed out of the final part and forms an integral part of it. The main advantage of liquid phase sintering is the very fast initial binding by capillary wetting, making it applicable with a fast moving laser beam. Full densification and strengthening of the porous green parts may still require post processing: either conventional furnace sintering to allow the LPS reaction to continue, or infiltration with another metal (e.g. Cu). The University of Leuven applied liquid phase laser sintering with good results to powder mixtures of $\mathrm{Fe}-\mathrm{Cu}$, Stainless Steel- $\mathrm{Cu}$ and hardmetal mixtures of $\mathrm{WC}-\mathrm{CO}, \mathrm{TiB}_{2}-\mathrm{Ni}$, $\mathrm{Fe}_{3} \mathrm{C}-\mathrm{Fe}$ [56]. Steel-Cu, steel-bronze and WC-Co blends have also been tested by other institutes $[13,48,87]$.

- True melting takes place at higher laser energy levels that totally melt and fuse the powder grains. It is more difficult to control in order to avoid balling of the melt and distortion of the part due to large shrinkage. However, the Fraunhofer Laser Institute (ILT) in Aachen proved that layer shrinkage during melting may be controlled to occur only vertically (no in-plane shrinkage), hence resulting in good parts with a green density close to $100 \%$ [5]. 


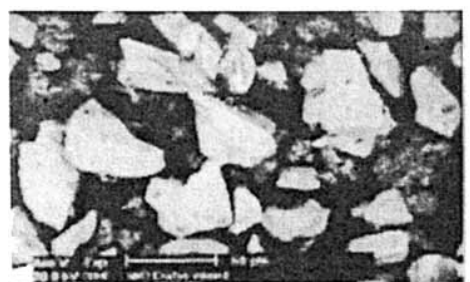

a1. WC and Co powder mix

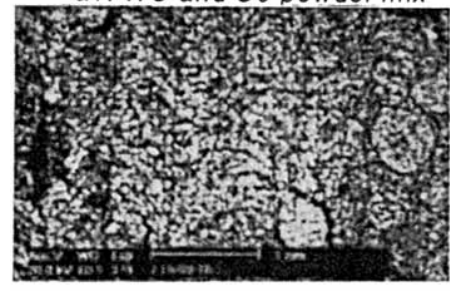

a2. Sintered powder mix

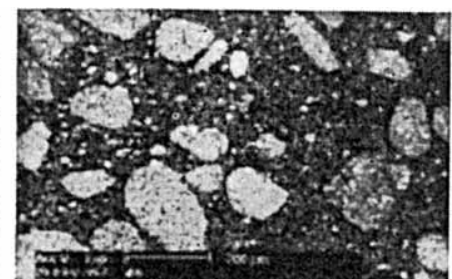

b1. Milled WC/Co powder

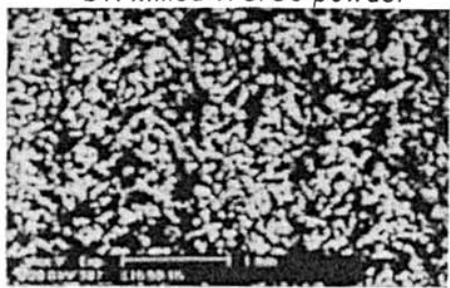

b2. Sintered milled powder

Fig. 24 SLS of mixed (unalloyed) and middel (alloyed) WC-Co powder (White =WC; Grey $=$ Co, Black $=$ pores $)$ (K.U.Leuven $)$

K.U.Leuven developed special mechanically alloyed powders (among others WC-Co composite powder - Fig. 24-b1) that yield higher SLS green densities and strength as compared to liquid phase SLS of mixtures of individual powder grains (WC and Co - Fig. 24-a1) [[58]. Mechanically alloyed powders are obtained by a high energy ball

milling process repeatedly breaking and welding a mixture of grains of the two constituent phases. Fig. 24-b2 clearly shows the higher density and finer micro-structure obtained with the mechanically alloyed powders.

At the university of Texas at Austin, a SLS/HIP process is being developed. In this process an impermeable skin is laser sintered around the shape of a complex part. The interior of the part is laser sintered to intermediate density. The encapsulated, partially sintered part is then processed by hot isostatic pressing (HIP) to full density [13].

Another recent evolution is laser sintering of foundry sand and ceramic (e.g. shells for investment casting). Laser sintering of zirconium sand $\left(\mathrm{ZrSiO}_{4}\right)$ and silica sand $\left(\mathrm{SiO}_{2}\right.$ crowning sand) have reached industrial practice, while research is going on with $\mathrm{ZrSi}$, $\mathrm{ZrSiO}_{4}, \mathrm{SiC}$, graphite and other types of ceramics [45].

\section{Laser Cladding (LC)}

Laser cladding, laser generating, CMB (Controlled Metal Buid-up), LENS (Laser Engineered Net Shape), SDM (Shape Deposition Modelling) and LAPS-J (Laser Aided Power Solidification with powder Jet) are processes in which powder material is sprayed through a nozzle into the spot of a laser beam focused on the workpiece (Fig. 25

and Table 3). In the CMB process (developed at IPT and commercialised by Röders, Germany [43]) and the SDM process (Stanford [20]), the relative inaccuracy of the powder jet deposition has been remedied by applying a milling operation that mills the contour and the upper surface of each layer before applying the next one (Fig. 26). Different solutions are used to support part overhangs: overhangs prohibited (Röders CMB process pertormed on 2.5-axis milling machine), use of 5-axis cladding machine, deposition of copper as support material (SDM process; copper removed by etching afterwards). The latter process also uses a 5-axis milling machine to remove stair-case effects at the contour of layers in slanted part areas.

The advantage of laser cladding is that through melting of the powder permits the generative manufacture of a metallic part with a dense homogeneous structure.

Another process is LaserCast [35] where parts of titanium and its alloys are formed by selective melting of powder in a fluidised bed.

\section{Laminated Object Modelling (LOM)}

LOM builds parts by stacking thin sheets or foils on top of each other, whose contours are cut according to the part's cross section (Fig. 27a). Some commercial machines (Helisys, Kinergy) supply the sheet material from a roll and use a $50 \mathrm{~W} \mathrm{CO}$ laser to cut the contour. in those systems, the adhesive is pre-applied over the whole sheet surface. A third commercial machine (Kira) uses $A 3$ paper sheets fed form a 'standard' copy machine unit that applies the adhesive selectively, only inside the part's contour. After pressing a new sheet onto the previous layers, the sheet is cut with a knife instead of a laser. A very economical A4 type machine is now on the market. The simplicity of this machine and its size make it suited as a concept modeller. A prototype variant of the SDM process, developed at the University of Utah, uses a heated wire to cut sheets of polymer foam [61].

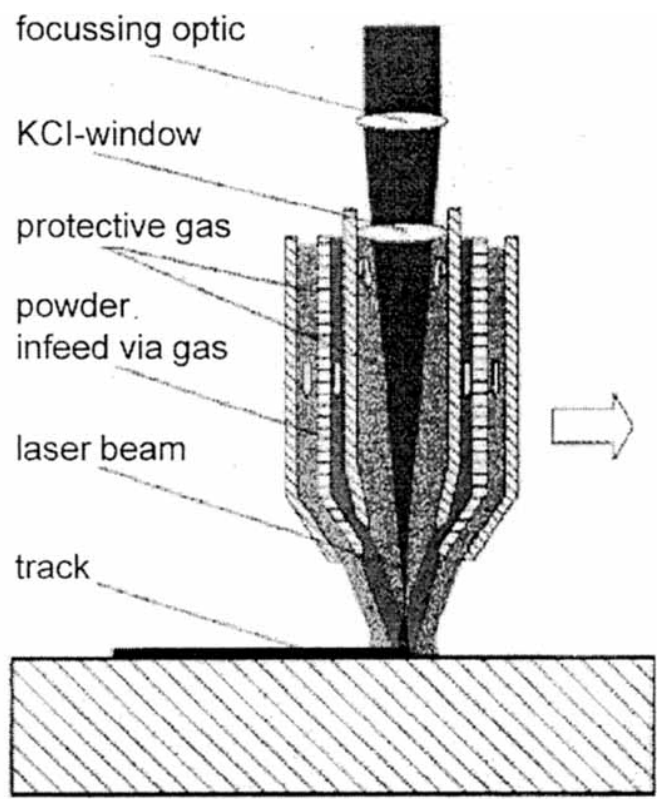

Fig. 25 : Powder fed into laser spot in CMB (IPT-Aachen) [44]. Until recently, all commercial systems used paper foils as material. This results in parts with properties similar to wood, especially after infiltration of the paper-like product with a pore filling varnish. The parts are strong, temperature resistant, but are sensitive to delamination and to moisture, which causes dimensional change. Sibco Inc. claims that their new paper material is much less sensitive to moisture. This paper material is also coated with adhesive but here a thermoplastic binder is used rather than a thermosetter which seems to improve machine re-starting behaviour.

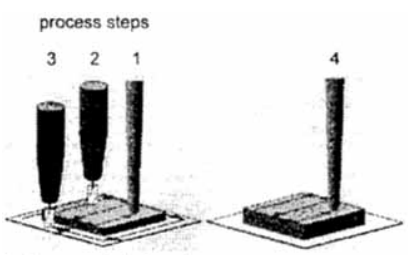

1. Laser cladding layner $n$

2. Milling to surface

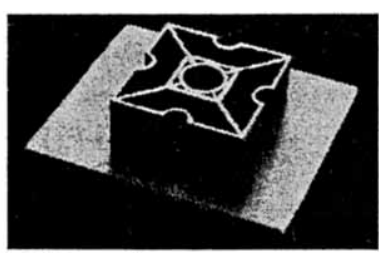

3. Milling contour

4. Laser cladding layer $n+1$
Fig. 26 : Laser cladding followed by milling in CMB [44] 
Kira investigated the possibilities to use plastic foils, but was refrained by cost considerations. Research carried out mainly at the University of Dayton and Helisys has resulted in various types of glass-fibre/polymer-matrix composite foils, some of which became commercially available recently. Those composite materials depict high strength, dimensional stability and/or impact resistance: see Fig. 27b. The paper offered by Helysis consists of non-woven, randomly-oriented long glass-fibres, coated at the lower surface with a thermosetting adhesive and at the upper surface with a proprietary acrylic binder to prevent sticking of the foil to the heated pressing roll [74]. Tests with prepregs of continuous unidirectional glass-fibre (52$55 \mathrm{vol} \%$ ) into an epoxy matrix, and with carbon/epoxy prepregs were less successful [47]. The same university investigated the use of LOM to fabricate monolithic ceramic parts (using ceramic tapes made from SiC powder, carbon powder and a polymer binder) and $\mathrm{SiC} / \mathrm{SiC}$ ceramic-matrix composite parts (using alternating $\mathrm{SiC}$ ceramic tapes and SiC-fibre/thermosetting-resin) [46]. To obtain the final ceramic part, a post process is applied involving pressing, heating, and reaction bounding. Alternatively $\mathrm{Al}_{2} \mathrm{O}_{3}$ ceramic was used instead of $\mathrm{SiC}$ [46]. Other developments aim at producing multi-material LOM parts [65].

Several researchers investigated the possibility to apply LOM to the production of metal parts by cutting metal foils to shape and joining them into a stack $[16,22,33,54,71]$. Cutting the metal foils is done with a $\mathrm{CO}_{2}$ or Nd:YAG laser, while binding the foils together is done either by laser spot welding, diffusion or blaze binding, brazing (using copper clad stainless steel sheets), mechanical clamping, or a combination of those (e.g. laser spot welding followed by diffusion or brazing in furnace). Most investigators applied steel sheets between 0.18 and 1 $\mathrm{mm}$. As expected in view of their higher reflectivity, $\mathrm{Al}$ and $\mathrm{Co}$ sheets
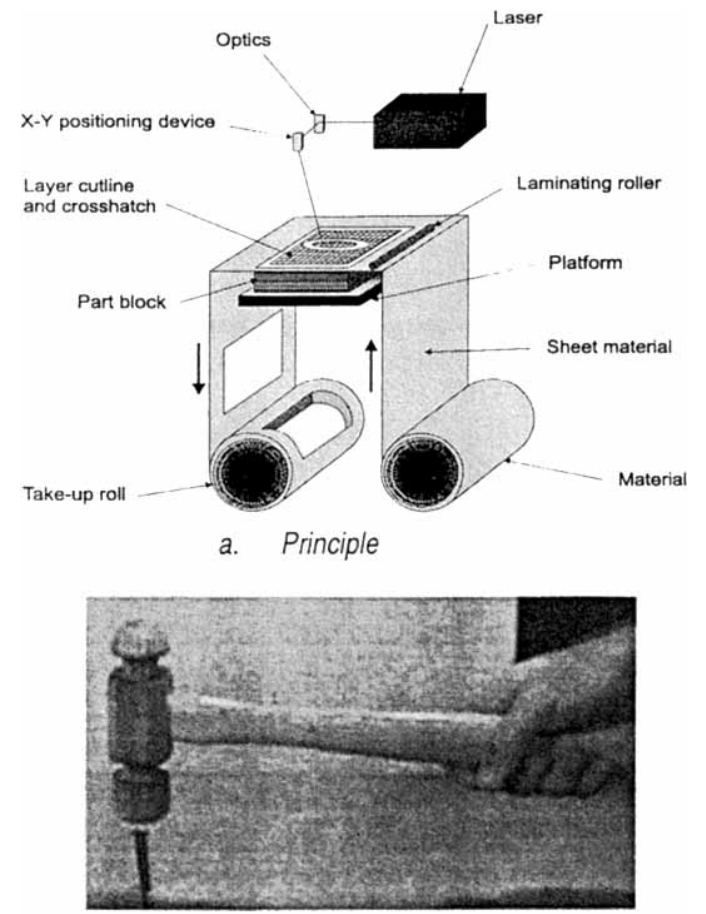

b. Composite hammer

Fig. 27 : Laminated Object Modelling (Helisys)

proved more difficult to laser cut and weld [7]. Different processing sequences were tried out: cut-before-weld or weld-before-cut, topsheet cutting or free-cutting. Metal sheet LOM was used successfully to produce plastic injection moulds, car body forming dies, deep drawing punches, press brake punches, etc. [55].

A new system, which is under development, is the non-planar LOM process [40]. The objective is to improve the strength and surface smoothness of shell like LOM part by applying fibre reinforced foils that follow the part's shape and curvature, so as to ensure the fibres to be langent to the shell. The curved laminated part is built by stretching and pressing successive composite or ceramic foils over a mandrel that has been previously prefabricated using the existing flat layer paper LOM process. The curved foils are pressed onto the mandrel by a heated elastomeric diaphragm. As co3mpared to flat LOM, this process poses some additional difficulties, like the need to have nonplanar CAD part slicing, and non-planar laser cutting [40].

\section{Laser Vapour Deposition}

The Max Planck Institute in Göttingen (Germany) and the University of Texas in Austin (USA) both developed rapid prototyping processes derived from the Laser Chemical Vapour Deposition process (LCVD). The process applied in Austin is called Selective Area Laser Deposition (SALD) [66]. This principle is used for free-form fabrication on microscale with part dimension from $10 \mu \mathrm{m}$ to $5 \mathrm{~mm}$. The process starts from a gas mixture that contains a complex combination of the elements (material) to be deposited. A scanning laser beam activates local thermal photo-decomposition of the gas into the elements of interest that are fixed onto the workpiece. For instance, starting from a gas mixture of ethylene, nickel tetracarbonyl and iron pentacarbonyl, FeNi objects are formed using an Argon-ion laser with 488/514 nm wavelength. Parts in SiC ceramics or in aluminium could be obtained by using resp. tertramethylsilane $\left(\mathrm{Si}\left(\mathrm{CH}_{3}\right)_{2}\right)$ or aluminiumtrihydride gas: Fig. 10. Even diamond could be deposited by working in an atmosphere containing hydrocarbons.

This principle can also be used for larger structures [31]. Here a frequency converted Nd:YAG laser at 532,355 , or $266 \mathrm{~nm}$ is used to deposit material layer by layer (SALD) or to fuse powder layers (SALDVI- Selective Area Laser Deposition Vapour Infiltration). With this technique it is possible to build parts with a size of $100 \times 100 \times 100$ $\mathrm{mm}$.

\section{Conclusion}

Since the first CIRP survey on rapid prototyping in 1991 [51], only few real new RP processes emerged. Notwithstanding, a lot of process variant and process improvements were conceived. Speed was multiplied by a factor of ten.

The most impressive novelties are probably related to the materials. Today's RP materials have much better mechanical, thermal and dimensional properties and the pallet of materials that can be processed covers nearly all materials. Process and malerial developments made RP suited to produce hardmetal, ceramic and composite parts that are difficult to tabricate with other techniques.

The range of applications was also extended to include functional technical parts, medical parts, rapid tooling, micro-fabrication, etc. although prototypes remain the main application.

In the early nineties, many manufacturing experts were sceptic towards the chance of those slow and inaccurate rapid prototyping processes to be good for any other purpose than producing look-at prototypes. Today, a great deal of the challenge has been won to turn additive manufacturing into a production technique with a wide scope of application that may further revolutionise the manufacturing world beyond the year 2000 .

The greatest challenge for the future probably is to further improve dimensional accuracy.

\section{References}

[1] Aganwala, M., et. al., 1995, Direct Selective Laser Sintering of Metals, Rapid Protot. J., 1/1:26-36 
[2] Agarwala, M.K. et al., 1996, Fused deposition of ceramics and metals, an overview. Proc. Solid Freeform Fabrication Symp., 385-392.

[3] André, J.C., 1992, Microstéréopholithographie, Recherches en Microtechniques, Réalités et Perspectives, Collections du lion vert, $73-78$

[4] Bakkelund, J., Karlsen, R., Bjørke, Ø., 1997, Fabrication Metal Objects Using Layer Manulacturing Technology and Powder Metallurgy Science, CIRP Annals, 46/1:135-138

[5] Behler, K., et. al., 1997, Trends of laser development and perspectives for the application, Proc. LANE'97, Laser Assisted Net shape Engineering 2, 129-142

[6] Behrendt, U., Shellabear, M., 1995, The EOS rapid prototyping concept, Computers in Industry, 28:57-61

[7] Chi, Ch., Dodin, L., Pak, S., 1997, Development and Fabrication of Metallic LOM Objects, Proc. $7^{\text {n }}$ Int. Conf. on Rapid Prototyping, 293-299

[8] Childs, T.H., Juster, N.P., 1994, Linear and geometric accuracies from layer manufacturing, CIRP Annals, 43/1: 163-166

[9] Christopherson, S., 1998, The machine that prototyped itself, Prototyping Technology International ' 98 , UK \& Intern. Press, Dorking, UK, 140-143

[10] Cohen, A., Zhang, G., Tseng, F.-G., 1998, EFAB: Batch production of functional, fully-dense metal parts with micronscale features, Proc. $9^{\text {n }}$ Solid Freetorm Fabrication Symp., August, Austin, Texas.

[11] Corby, Th., 1997, Frozen-stress photoelastic analysis of rapid prototype stereoltihography models, Proc. $7^{\text {th }}$ Int. Cont. on Rapid Prototyping, 112-121

[12] Crump, S, 1992, Apparatus and method for creating threedimensional objects, US patent 5121329

[13] Das, S, Harlan, N, Beaman, J.J, Bourell, D.L., 1996, Selective Laser Sintering of High Performance High Temperature Metals, Proc. Solid Freeform Fabrication Symp., 89-95.

[14] Dauw, D.F., Albert, L., 1992, About the evolution of wire tool performance in Wire EDM, CIRP Annals, 41/1: 221-226

[15] Deckard, C.R., Beaman, J.J., 1987, Recent Advances in Selective Laser Sintering. Proc. $14^{\mathrm{t}}$ Conf. on Prod. Res. and Technology, , 447-451.

[16] Dormal, Th., Dam, J.L., Baraldi, U., 1998, A new technology for the manufacturing of large protolype injection moulds: LLCC (Laminated Laser Cut Cavities), Proc. $7^{\text {th }}$ Eur. Conf. on Rapid Prototyping and Manufacturing, 327-336

[17] Dutta, D., Kulkami, P., 1997, Improving surface quality and throughput in layered manufacturing by adaptive slicing, Proc.

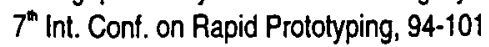

[18] Eschl, J., Dusel, K.-H., Eyerer P., 1997, Simulation of the mechanical behavior of stereolithography resins during the curing process, Proc. $7^{\text {th }}$ Int. Conf. on RP, 157-161

[19] Fessler, J., Nickel, G., Link, G., Prinz, F., Fussel, P., 1998, Functional Gradients in Melallic Prototypes, Prototyping Technology International '98, UK \& Intern. Press, Dorking, UK, 160-163

[20] Fessler, J.R. et al., 1996, Laser deposition of metals for Shape Deposition Manufacturing (SDM), Proc. Solid Freeform Fabrication Symp., 117-124

[21] Fodran, E., Koch, M., Menon, U., 1996, Mechanical and dimensional characteristics of FDM build styles, Proc. Solid Freeform Fabrication Symp., 419-442.

[22] Franke, V., Greska, W., Geiger, M., 1994, Laminated tool system for press brakes, Proc. Lane'94, Laser Assisted Net Shape Engineering, Vol. 1: 883-892

[23] Gatto, A., Iuliano, L., Settineri, L., 1998, Particles' Formation and Deposition in the Sanders RP Process, Proc. $7^{\text {h }}$ Europ. Cont. on Rapid Protot. and Manut.,211-227
[24] Geiger, M., Coremans, A., Neubauer, N., Niebling, F., 1996, Advanced Rapid Prototyping by laser beam sintering of metal prototypes - design and development of an optimised laser beam delivery system, Europ. Symp. on Lasers, Optics and Vision for Productivity in Manufacturing II

[25] Gervasi, V.R., ot.al., 1997, TetraCast SLA Build Style, $7^{\text {h }}$ Int. Conf. on Rapid Prototyping, 309-317

[26] Greer, C., McLaurin, J., Ogale, A., 1996, Processing of carbon fiber reinforced composites by three dimensional photolithography, Proc. Solid Freeiorm Fabrication Symp., 307 410

[27] Greul, M., Sindel, M., Geiger, M., 1994, Multiphase Jet Solidification (MJS) - A New Rapid Prototyping Process tor Metal and Ceramic Parts, Proc. $3^{\text {th }}$ Europ. Conf. on Rapid Prototyping and Manufacturing, 257-260

[28] Griffith, M.L., Halloran, J.W., 1994, Ultraviolet curable ceramic suspensions for Stereolithography of ceramics, Manufacturing Science and Engineering, ASME, PED-Vol. 68/2:529-534

[29] Grimm, T., 1997, SLS and SLA, different technologies for different applications, Prototyping Technology International ' 97 , UK \& Intern. Press, Dorking, UK, 130-138.

[30] Hague, R., Dickens, Ph., 1997, Design of New Build Structures for the Successful Autoclaving of Stereolithography Models, $7^{\text {th }}$ Int. Conf. on Rapid Prototyping, 192-202

[31] Harrison, S., Crocker, J.E., Manzur, T., Marcus, H.L., 1996, Solid freefrom fabrication at the university of Connecticut, Proc. Solid Freetorm Fabrication Symp., 345-348.

[32] Himmer, T., Nakagawa, T., Noguchi H., 1997, Stereolithography of ceramics, Rapid Prototyping, Vol. 3(3): 1-4

[33] Himmer, TH., Nakagawa, T., Mohri, N., 1998, Rapid Die Manufacturing System, Proc. $7^{\text {th }}$ Europ. Conf. on Rapid Prototyping and Manufacturing, 315-326

[34] Hinczewski, C., Corbel, S., Chartier, T., 1998, Stereolithography for the fabrication of ceramic three dimensional parts, Proc. $7^{\text {th }}$ Europ. Conf. on Rapid Prototyping and Manufacturing, 247-258

[35] House, M.A., Whitney, E.J., Krantz, D.G., Arcella, F.G., 1996, Rapid laser forming of titanium near shape articles: LaserCast. Proc. Solid Freeform Fabrication Symp., 239-248.

[36] Ikuta, K., Hirowatari, K., Real Three Dimensional Micro Fabrication using Stereolithography and Metal Molding, Dep. Mech. Sys-tem Eng., Kyushu Institute of Technology, Fukuoka 820, Japan

[37] Jacobs, P., 1997, Recent advances in rapid tooling from stereolithography, Proc. $7^{\text {th }}$ Int. Conf. on Rapid Prototyping, 338-354

[38] Jacobs, P.F., 1992, Rapid Prototyping and Manufacturing: fundamentals of stereolithography, Society of Manufacturing Engineers, Dearborn

[39] Jafari, M., Safari, A., Danforth, S., Langrana, N., 1998, Advanced machine and process control in layered manufacturing, Proc. $7^{\text {th }}$ Europ. Conf. on Rapid Prototyping and Manufacturing, 75-82

[40] Kalmanovich, G., 1996, Curved layer LOM, Proc. Solid Freeform Fabrication Symp., 273-280.

[41] Kimura, F., 1997, Issues in styling and engineering design, CIRP Annals, 46/2:527-534.

[42] Kishinami, T., Tanaka, F., 1997, Distortion Mechanism of stereolithography parts, Proc. 8th ICPE-conf. Rapid Product Development, Chapman \& Hall, 83-92

[43] Klocke, F., Clemens, U., 1996, Rapid Tooling Combining Laser

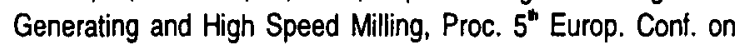
Rapid Prototyping and Mfg., 211-221.

[44] Klocke, F., Clemens, U., 1997, An RP network for product development, Prototyping Technology International '97, UK \& Intern. Press, Dorking, UK, 57-60 
[45] Klocke, F., Wirtz, H., 1997, Selective Laser Sintering of Ceramics, Proc. LANE'97, Laser Assisted Net shape Eng. 2, 589-596

[46] Klosterman, K.A. et al., 1996, Structural composites via Laminated Object Manufacturing (LOM), Proc. Solid Freeform Fabrication Symp., 105-116.

[47] Klosterman, D., Priore, B., Chartoff, R., Laminated Object Manufacturing of Polymer Matrix Composites, 1997, Proc. $7^{\text {th }}$ Int. Conf. on Rapid Prototyping, 283-286

[48] Kräupl, S., Hotfmann, P., 1997, New developments for laser sintering of metallic powders, LANE'97, Laser Assisted Net shape Eng. 2, 609-614

[49] Krause, F.L., 1997, Design and information management for rapid product development, 1997, Proc. 8th ICPE-conf. Rapid Product Development, Chapman \& Hall, 17-28

[50] Krause, F.L., Ulbrich, A., Ciesla, M., Klocke, F., Wirtz, H. , 1997, Improving Rapid prototyping processing speeds by adaptive slicing, Proc. $6^{\text {th }}$ Eur. Conf. on Rapid Prototyping and Manuf., 31-36

[51] Kruth J.-P., 1991, Material incress manufacturing by rapid prototyping techniques, CIRP Annals 40/2, 603-614.

[52] Kruth, J.-P., 1995, New applications of physical and chemical processes for material accretion manufacturing, Proc. $11^{\text {th }}$ Int. Symp. for Electro-Machining, 3-29.

[53] Kruth, J.P., Meyvaert, I., Vandormael, P., Renap, K., 1997, Curtain Coating for Depositing Layers in Stereolithography, Proc. $7^{\text {th }}$ Int. Conf. on Rapid Prototyping, 218-228.

[54] Kruth, J.-P., Van der Schueren, B., 1995, Direct production of metallic parts by rapid prototyping, $12^{\text {th }}$ Int. Congress LASER 95, Key technology Laser: Challenge for the Factory 2000, 132 . 134.

[55] Kruth, J.P., Van der Schueren, B., 1997, Soft and hard rapid tools for polymer and metal casting/moulding, Proc. Colloquium EMO Hannover, 'Werkzeugbau - eine Branche mit Zukunft', 175-194

[56] Kruth, J.-P., et. al., 1996, Basic powder metallurgical aspects in Selective Metalpowder Sintering, CIRP Annals 45/1:183-186

[57] Laoui, T., Kruth, J.P., Froyen, L., 1998, Influence of powder para-meters on selective laser sintering of tungsten carbide cobalt, Proc. $7^{\mathrm{t}}$ Europ. Conf. on Rapid Prototyping and Manuf. 271-280

[58] Laoui, T., Froyen, L., Kruth, J.P ,1998, Effect of Mechanical Alloying on Selective Laser Sintering of WC/9Co Hard Metal Powder, submitted to ${ }^{\circ}$ Powder Metaliurgy World Congress, Granada, Oct., 18-22

[59] Lauwers, B., Meyvaert, 1., Kruth, J.P., 1997, Layer deposition in SLA and SLS, Prototyping Technology International '97, U.K. \& Intern. Press, Dorking, 139-144.

[60] Lee, K., Hur, J., Kim. G., Computing environment to facilitate stereolithographic rapid prototyping, 1997, Proc. 8th ICPE-cont. Rapid Product Development, Chapman \& Hall, 103-112

[61] Leu, M.C., Zhang, W., 1998, Research and development in rapid prototyping and tooling in the United States, Proc. Int. Conf. on Rapid Prototyping and Manufacturing, Beijing, July 21 . 28

[62] Li, L., Ng, K.L., Slocombe, A., 1998, Diode Laser Sintering of Compacted Metallic Powders For Desk Top Rapid Prototyping,

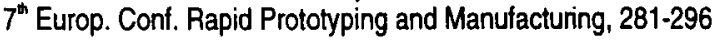

[63] Marutani, Y., Kamitani, T., 1996, Stereolithography system using multiple spot exposure, Proc. Solid Freeform Fabrication Sym-posium, 321-326

[64] Marutani, Y., Kamitani, T., 1997, 3-Dimensional Exposure Using an Air Bubble in the Resin, Proc. $7^{\text {t }}$ Int. Conf. on Rapid Prototyping, 213-217.
[65] Mathewson, B., Choi, S., Newman, W., Cawley, J., Heuer, A., Machine design, control and performance of automated computer-aided manufacturing of laminated engineering materials, Proc. $9^{\text {th }}$ Solid Freeform Fabrication Symp., August, Austin, Texas.

[66] Maxwell, J.L., Pegna, J., Messia, D., DeAngelis, D., 1996, Direct feedback control of gas phase laser induced deposition, Proc. Solid Freeform Fabrication Symp., 227-238.

[67] McAlea, K., et. al., 1997, Materials and applications for the Selective Laser Sintering Process, Proc. $7^{n}$ Int. Conf. on Rapid Prolotyping, 23-33.

[68] Mickish, S.J., 1995, DuPont Somos materials for layer manufacturing, 4èmes Assises Européennes du Prototypage Rapide

[69] NN, 1997, Three dimensional Fax technology for concurrent engineering, IWT project ITA/950221/Materialise, K.U.Leuven, Year report $96-97$

[70] Murakami, T., et.al., 1997, Refrigerative stereolithography for rapid product prototyping, Rapid Product Development, Chapman \& Hall, 73-82

[71] Nakagawa, T., 1994, Application of laser beam cutting to manufacturing of forming tools, Proc. LANE'94, 871-882

[72] Nakagawa, T., et.al., 1997, Overview of rapid prototyping research and development in Japan, Rapid Product Development, Chapman \& Hall, 3-16

[73] Novac, A., et.al., 1997, Automated technique for adaptive slicing in layered manufacturing, Proc. $7^{\text {th }}$ Int. Conf. on Rapid Prototyping, 85-93

[74] Ogg, J.M., 1998, Composite Successful for Tooling, Rapid Prototyping International'98, UK \& Intern. Press, 40-43

[75] Partanen, J., 1996, Solid state lasers for Stereolighography, Proc. Solid Freelorm Fabrication Symp., 369-376.

[76] Renault, T., et.al., 1996, Selective reinforcement of photoresins with continuous fibers using $3 \mathrm{D}$ composite photolithography, Journal of Advanced Materials, 8-12.

[77] Sachs, E. et.al., 1994, 30 Printing of Functional Parts and Tooling, Proc. IMS Int. Conf. On Rapid Product Development, Stuttgart, 93-106

[78] Sachs, E., et.al., 1990. Three-Dimensional Printing: Rapid Tooling and Prototypes Directly from a CAD Model, CIRP Annals, 39/1:201-204

[79] Sachs, E., et.al., 1996, Rapid Fabrication of Injection-Molding Tooling with 3D Printing, Rapid Prototyping, Vol. 2, Nr. 4, 1-3

[80] Safari, A., Danforth, S.C., 1998, Processing of advanced functio-nal ceramic components by solid freeform fabrication (SFF) tech-niques, Proc. $7^{\text {th }}$ Europ. Conf. on Rapid Prototyping and Manuf., 259-270

[81] Schultz, J.W., et.al., 1998, Novel resins for stereolithography, Prototyping Technology International '98, U.K. \& Intem. Press, 178-185

[82] Schumacher, B.M., Levy, G.N., 1998, Selective Laser Sintering combined with systematic development of new powders enabling innovative and prosperous redesign of processlayouts, Proc. $12^{\text {th }}$ Int. Symp. for Electro-Machining, 633-639

[83] Seitz, S., et. al., 1997, New Materials for New Applications in SLS.Proc. LANE'97, 623-628

[84] Shellabear, M., 1997, Beyond RP: Laser sintering for tooling and manufacture, Rapid Prototyping International ' 97 , UK \& Int. Press, U.K, 147-150

[85] Shu, Ch., Mak, H., Tessellating STEP B-Rep Models, 1997 Proc. $7^{\text {t }}$ Int. Conf.on Rapid Prototyping, 70-78

[86] Sitzmann, E.V., Haynes, R.L., Anderson, R.F., 1995, Exactomer resins for high accuracy Stereolithography, 4èmes Assises Européennes du Prototypage Rapide

[87] Song Yong-Ak, 1996, Selektives Lasersintern metallischer Proto-typen, Ph.D thesis RWTH Aachen 
[88] Song, W.Q., Masood, S.H., Hodgkin, J.H., Friedl, Ch., 1998, Development of metal-polymer composites for fused deposition modelling, Proc. $7^{\text {th }}$ Eur. Conf. on Rapid Protot. and Mfg., 239246

[89] Steinmann, B., Schulthess, A., Hofmann, M., 1995, Epoxy resins for stereolithography and some new applications, $4 e$ Assises Eur. du Prototypage Rapide

[90] Stoddart, R.D., 1997, Drop on demand yields precision tooling patterns, Prototyping Technology International ' 97 , UK \& Intern. Press, Dorking, UK, 224-227

[91] Swaelens, B., Pauwels, J., Vancraen, W., 1995, Support generation for Rapid Prototyping, Proc. $6^{\text {th }}$ Int. Conf. on Rapid Prototyping, 115-122

[92] Swaelens, B., Vancraen, W., 1997, Laser Photopolymerisation Models based on Medical Imaging : a Development improving the Accuracy of Surgery, Proc. $7^{\text {th }}$ Int. Conf. on Rapid Prototyping, 250-260

[93] Tyberg, J., Bohn, J.H., 1998, Local adaptive slicing, Proc. $7^{\text {th }}$ Europ. Cont. on Rapid Prototyping and Manufacturing, 127-143

[94] Ullett, J.S. et al., 1996, Low shrinkage, high $T_{\text {, liquid crystal }}$ resins for Stereolithography, Proc. Solid Freeform Fabrication Symp., 471-479.

[95] Ullett, J.S., Schultz, J.W., Chartoff, R.P., 1997, Advanced high temperature resins for Stereolithography, Proc. $7^{\mathrm{h}}$ Int. Conf. on Rapid Prototyping, 203-212

[96] Van der Schueren, B., 1996, Basic contributions to the development of the Selective Metal powder Sintering process, Ph.D. thesis 96D5, K.U. Leuven

[97] Van der Schueren, B., Geling, J., 1998, Parts to go. Prototyping Technology International '98, UK \& Intern. Press, Dorking, UK, 48-52

[98] Van der Schueren, B., Kruth, J.-P., 1995, Design aspects of a 'Selective Metal Powder Sintering' apparatus, Proc. of $11^{\text {th }}$ Int. Symp. for Electro-machining (ISEM-XI), 651-662

[99] Westkämper, E., 1997, Direct Manufacturing of Metal and Ceramic Prototypes by "Multiphase Jet Solidification", Proc. $8^{\text {th }}$ Int. Conf. on Production Engineering, 123-131

[100] Wilkening, C., 1996, Fast production of technical prototypes using direct laser sintering of metals and foundry sand, Proc. Solid Freeform Fabrication Symp., 133-140

[101] Wohlers, T., 1998, State of the Industry Report - Executive Summary, Proc. Rapid Prototyping and Manufacturing'98 Conf., SME, 951-962

[102] Xu, F., Wong, Y.S., Loh, H.T., Fuh J.Y., Optimal orientation with adaptive slicing for part building in SLA, 1997, Proc. $7^{\text {th }}$ Int. Conf. on Rapid Prototyping, 148-156

[103] Yamaguchi, K., Nakamoto, T., 1997, Manufacturing of unidirectional whisker reinforced plastic microstructures, Proc. $8^{\text {th }}$ ICPE, Rapid Product Development, Chapman \& Hall, 159-168

[104] Zeneca, priority date 2-7-93, SL production of selectively coloured 30 articles using compositions containing a colour former and an infrared absorber, patent number WO/9894/01427

[105] Zhang, W., Leu, M., Ji, Z., Yan, Y., Yao, W., Yang, B., 1998, Rapid freezing prototyping with water, Proc. $9^{\text {h }}$ Solid Freeform Fabrication Symp. , August, Austin, Texas.

[106] Zissi, S., Jézéquel, J.Y., Corbel S., André J.C., 1995, Bounds of laser stereophotolithography in its microtechnical applications, Proc. $11^{\text {th }}$ Int. Symp. for ElectroMachining, ISEM XI, 641-649 